ARTICLE

httpst//doi.org/10.1038/s41467-020-17231-3

\title{
Operando time-resolved X-ray absorption spectroscopy reveals the chemical nature enabling highly selective $\mathrm{CO}_{2}$ reduction
}

\author{
Sheng-Chih Lin ${ }^{1,6}$, Chun-Chih Chang (i) ${ }^{2,6}$, Shih-Yun Chiu', Hsiao-Tien Pai ${ }^{3}$, Tzu-Yu Liao', Chia-Shuo Hsu (1) 1 , \\ Wei-Hung Chiang ${ }^{4}$, Ming-Kang Tsai (1) ${ }^{3 凶}$ \& Hao Ming Chen (i) $1,5 \bowtie$
}

Copper electrocatalysts have been shown to selectively reduce carbon dioxide to hydrocarbons. Nevertheless, the absence of a systematic study based on time-resolved spectroscopy renders the functional agent-either metallic or oxidative Copper-for the selectivity still undecidable. Herein, we develop an operando seconds-resolved X-ray absorption spectroscopy to uncover the chemical state evolution of working catalysts. An oxide-derived Copper electrocatalyst is employed as a model catalyst to offer scientific insights into the roles metal states serve in carbon dioxide reduction reaction $\left(\mathrm{CO}_{2} \mathrm{RR}\right)$. Using a potential switching approach, the model catalyst can achieve a steady chemical state of half- $\mathrm{Cu}(0)$ and-half- $\mathrm{Cu}(\mathrm{I})$ and selectively produce asymmetric $\mathrm{C}_{2}$ products $-\mathrm{C}_{2} \mathrm{H}_{5} \mathrm{OH}$. Furthermore, a theoretical analysis reveals that a surface composed of $\mathrm{Cu}-\mathrm{Cu}(\mathrm{I})$ ensembles can have dual carbon monoxide molecules coupled asymmetrically, which potentially enhances the catalyst's $\mathrm{CO}_{2} \mathrm{RR}$ product selectivity toward $\mathrm{C}_{2}$ products. Our results offer understandings of the fundamental chemical states and insights to the establishment of selective $\mathrm{CO}_{2} \mathrm{RR}$.

\footnotetext{
${ }^{1}$ Department of Chemistry, National Taiwan University, Taipei 10617, Taiwan. ${ }^{2}$ Department of Chemical and Material Engineering, Chinese Culture University, Taipei 11114, Taiwan. ${ }^{3}$ Department of Chemistry, National Taiwan Normal University, Taipei 11677, Taiwan. ${ }^{4}$ Department of Chemical Engineering, National Taiwan University of Science and Technology, Taipei 10607, Taiwan. ${ }^{5}$ National Synchrotron Radiation Research Center, Hsinchu 30076, Taiwan. ${ }^{6}$ These authors contributed equally: Sheng-Chih Lin, Chun-Chih Chang. ${ }^{凶}$ email: mktsai@ntnu.edu.tw; haomingchen@ntu.edu.tw
} 
f versatility, energy efficiency, and cost effectiveness, electrochemical $\mathrm{CO}_{2}$ reduction $\left(e \mathrm{CO}_{2} \mathrm{RR}\right)$ has been deemed a potential strategy to mitigate excessive anthropogenic $\mathrm{CO}_{2}$ emissions ${ }^{1-8}$. From a variety of catalysts for $\mathrm{eCO}_{2} \mathrm{RR}$, those copper-based have drawn much attention ${ }^{1,6}$, since $\mathrm{Cu}$ is the one which can electrochemically reduce $\mathrm{CO}_{2}$ molecules to economically favorable and energy-dense $\mathrm{C}_{2}$ products, such as $\mathrm{C}_{2} \mathrm{H}_{4}$ and $\mathrm{C}_{2} \mathrm{H}_{5} \mathrm{OH}^{5,9}$. However, the typically low product selectivity hinders the catalysts from industry applications. There, accordingly, have been numerous studies on improving the selectivity by means of nanostructuring ${ }^{10,11}$, bimetallic systems ${ }^{12-14}$, and oxidative modifications ${ }^{15-18}$. Among them oxidative modifications have received considerable attention, since they could significantly improve the selectivity of $\mathrm{Cu}$-based catalysts toward valuable $\mathrm{C}_{2}$ products.

Nevertheless, despite showing improvements, these oxidative modifications still cannot meet the decent selectivity for industry applications, $90 \%$ as Jouny et al. pointed out ${ }^{5}$. It has been noticed that these studies, whether knowingly or otherwise, suggested that $\mathrm{Cu}(\mathrm{I})$ may play a critical role in improving the selectivity toward $\mathrm{C}_{2}$ products, but the chemical state of $\mathrm{Cu}$ in the catalysts were varied drastically during electrochemical reduction by using a chronoamperometry 15,18 . This ineffective control of the chemical compositions and/or chemical states leads to the resulting low selectivity toward $\mathrm{C}_{2}$ products, and a fair speculation could be that a stable chemical composition of $\mathrm{Cu}$ species during electrolysis is indispensable to enhance the related $C_{2}$ product selectivity. For instance, Nogami et al. showed that an oxidation process stimulated by switching applied potentials in corresponding time intervals could bring an improvement in the product selectivity in their $\mathrm{eCO}_{2} \mathrm{RR}$ system ${ }^{19}$. Recent studies also agreed with the integrated oxidation process for improving $\mathrm{CO}_{2} \mathrm{RR}$ product selectivity ${ }^{20-23}$. For example, the employment of pulses voltage has been revealed to enhance the selectivity toward the $C_{2}$ products on polycrystalline $\mathrm{Cu}^{21,23,24}$. Recently, we have justified the existence of another competing reaction (i.e., the spontaneous oxidation of $\mathrm{Cu}(0)$ in aqueous electrolyte) that significantly governs the chemical state of active centers of $\mathrm{Cu}$, establishing a strong correlation between the chemical state under reaction conditions and the $\mathrm{CO}_{2} \mathrm{RR}$ product profile ${ }^{25}$. A similar effect has been also revealed in the case of Fe single atom catalyst, in which the reduction activity toward $\mathrm{CO}$ is evidently dominated by the chemical state of metal centers ${ }^{26}$.

However, some studies brought a different perspective that the active catalyst is metallic copper because no significant concentration of residual oxide was detected in the oxidederived samples; ambient pressure X-ray photoelectron spectroscopy (XPS) and electron energy loss spectroscopy (EELS) proved the absence of residual copper oxide in the reduced electrocatalyst ${ }^{27,28}$. Regarding this controversial issues, we have to point out a paramount subject concerning a significant mismatch in time-scale of acquiring spectrum. For conventional X-ray absorption spectroscopy (XAS), the spectroscopic acquiring time is approximately several $10 \mathrm{~min}$ (normally 20-30 min). In the cases of XAS and EELS, both of them would require a time-scale in minutes at least for spectrum acquisition. Notably, the chemical state of metal centers could reach a steady state in a few minutes under the $\mathrm{eCO}_{2} \mathrm{RR}$; as revealed by in situ Raman, the $\mathrm{CuO}_{\mathrm{x}}$ precursor would achieve a steady-state condition due to the co-occurrence of electrochemical reduction and of spontaneous oxidation caused by the trace oxidant in the electrolyte ${ }^{25}$. Consequently, a time-resolved identification of the characteristics in chemical state of metal centers should be highly desirable, especially for a time-scale of few seconds for revealing the real dominated factor in $\mathrm{CO}_{2}$ reduction electrocatalysis.
Thus far, there have been various types of time-resolved XAS developed. For example, the fixed energy X-ray absorption voltammetry (FEXRAV) has demonstrated its capability to provide valency information of a material under time-dependent electrochemical working conditions ${ }^{29-31}$. Another technique in the time-resolved XAS family is energy-dispersive XAS (EDXAS). The parallel acquisition of all data points in a XAS spectrum using EDXAS allows its time resolution down to the level of ms and, if possible, to $\mathrm{ps}^{32}$. While the FEXRAV and the EDXAS are of time resolution, certain drawbacks make both of them possibly not suitable for the present study. In the case of the FEXRAV, it fails to offer the information regarding chemical surroundings, which has been reported to influence the selectivity of a catalyst ${ }^{33,34}$ and normally can be derived using EXAFS spectroscopy. These technical limitations can be well removed by using quick-XAS. The basic setup for quick-XAS is shown in Fig. 1a. Via a quick-scanning monochromator, an acquisition time of a single XAS spectrum, including X-ray absorption near edge structure (XANES) and extended X-ray absorption structure (EXAFS), can be cut down to a few seconds, reaching secondsresolution. Moreover, its sequential detection mode also renders the operando detection achievable. Overall, the advantage of data collection and interpretation makes quick-XAS (TR-XAS hereafter) the time-resolved technique of choice in present study.

Herein, utilizing TR-XAS with a small X-ray incident angle, we develop an operando methodology to realize the seconds-resolved near-surface investigations of materials under $\mathrm{CO}_{2} \mathrm{RR}$ working conditions (Fig. 1a, b). This allows us to in situ characterize the chemical nature of catalytic surfaces. An oxide-derived $\mathrm{Cu}$ electrocatalyst with great potentials to produce hydrocarbons is employed as a model to provide scientific insights to the roles of metal states in $\mathrm{CO}_{2} \mathrm{RR}$. We can conclude that chemical state of copper ions can reach a steady-state in $\sim 5 \mathrm{~min}$ toward the metallic $\mathrm{Cu}(0)$ under a conventional chronoamperometry. Most interestingly, by utilizing a potential switching approach, the $\mathrm{Cu}$ (I) $/ \mathrm{Cu}(0)$ redox could achieve a steady state of half-and-half during a cathodic $\mathrm{CO}_{2} \mathrm{RR}$ electrolysis, producing an asymmetric $\mathrm{C}_{2}$ product $-\mathrm{C}_{2} \mathrm{H}_{5} \mathrm{OH}$ - with fairly high selectivity in a wide potential range. Furthermore, a theoretical computation revealed that a surface composed of $\mathrm{Cu}-\mathrm{Cu}(\mathrm{I})$ ensembles could have dual CO molecules coupled asymmetrically, which potentially enhanced the catalyst's $\mathrm{CO}_{2} \mathrm{RR}$ product selectivity toward $\mathrm{C}_{2}$ products $^{35}$. Operando TR-XAS gives conclusive evidence that chemical state of copper significantly dominates the catalytic behavior and the product profile of $\mathrm{CO}_{2} \mathrm{RR}$. Our results can offer understandings of the fundamental chemical state and insights into the establishment of selective $\mathrm{eCO}_{2} \mathrm{RR}$.

\section{Results}

Catalyst synthesis and characterization. A two-stage wet chemical synthesis was employed to realize our model catalyst. Uniform $\mathrm{Cu}$ nanocubes were first synthesized with an average size of $38.0 \pm 4.2 \mathrm{~nm}$ (Fig. 1c, and Supplementary Figs. 1 and 2). To investigate the individual role of $\mathrm{Cu}(0)$ and $\mathrm{Cu}(1+), 1$ hexadecylamine (HDA) was utilized to mediate the oxidation rate of targeted metallic nanomaterials and to gently oxidize the asprepared $\mathrm{Cu}$ nanocubes ${ }^{36}$, which protected the morphologies of the as-prepared nanomaterials from being crushed and further suppressed the effects caused by morphologies of materials ${ }^{37}$. TEM image of the oxidation modified $\mathrm{Cu}$ nanocubes $\left(\mathrm{CuO}_{x}\right.$ hereafter) clearly demonstrated that the morphology of $\mathrm{CuO}_{\mathrm{x}}$ stayed a cube-like after the oxidation modification (Fig. 1d). Regarding the chemical composition of the as-prepared $\mathrm{CuO}_{\mathrm{x}}$, selected area electron diffraction (SAED) was characteristic of two domains, metallic $\mathrm{Cu}$ and oxide $\mathrm{Cu}_{2} \mathrm{O}$ species, in the $\mathrm{CuO}_{\mathrm{x}}$ 
a

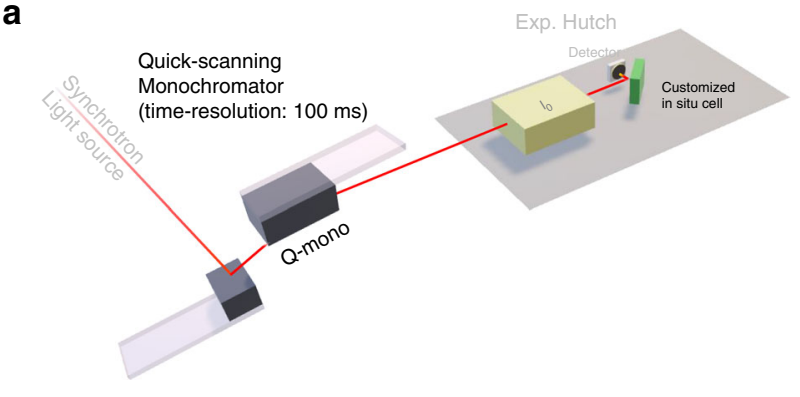

C

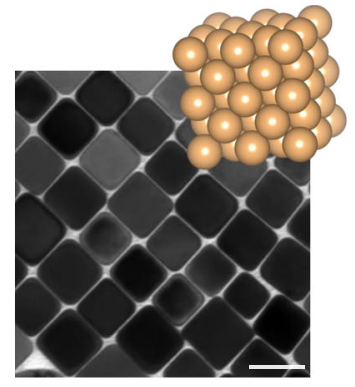

f

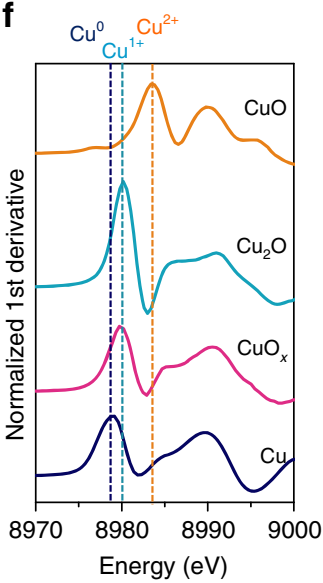

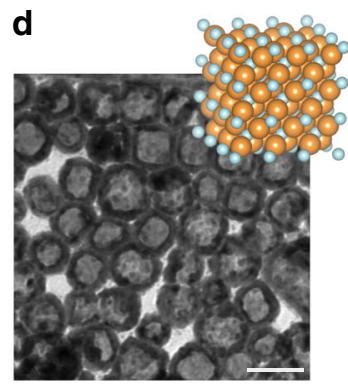

g

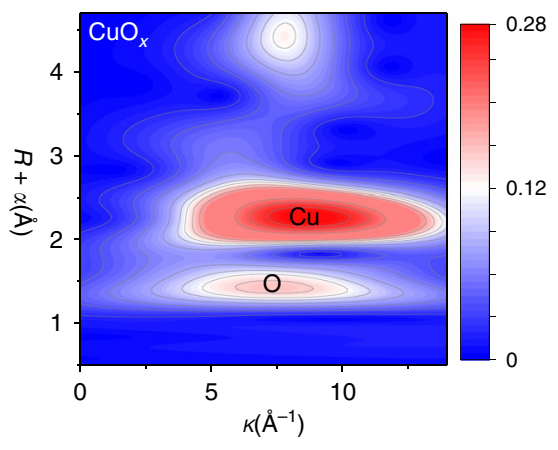

b

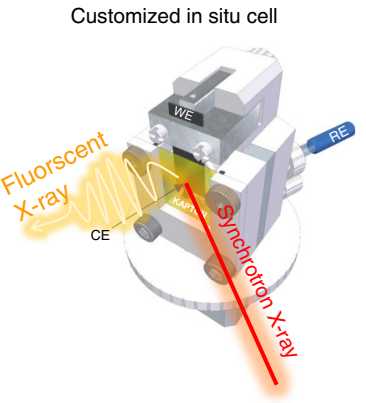

e

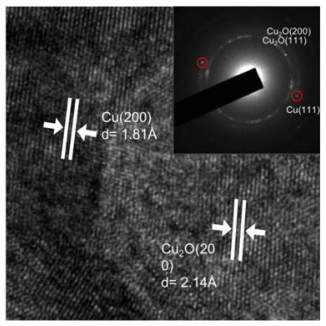

h

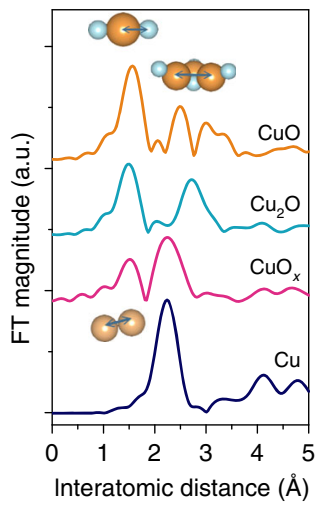

Fig. 1 Experimental setup and catalyst characterization. a The schematic diagram of the setup of operando time-resolved XAS experiments. $\mathbf{b}$ The cartoon representation of customized operando XAS cell. c TEM image of Cu nanocubes. d TEM image of CuO. Scale bars are $50 \mathrm{~nm}$. e HR-TEM image and SAED pattern (inset) of $\mathrm{CuO}_{x}$. $\mathbf{f}$ First derivatives of the $\mathrm{Cu}$ K-edge XANES spectra of $\mathrm{CuO}_{x}$ and of commercial $\mathrm{Cu}, \mathrm{Cu}_{2} \mathrm{O}$, and $\mathrm{CuO}$ as references. $\mathbf{g}$, $\mathbf{h}$ Wavelet transform-EXAFS of as-prepared $\mathrm{CuO}_{x}$ and the references.

(Fig. 1e). These observations confirm the formation of our desired material made of $\mathrm{Cu}-\mathrm{Cu}(\mathrm{I})$ ensemble. Electrochemical analyses also agreed with the electron microscopic analysis. Shown in Supplementary Fig. 3a, the LSV indicated at $-0.45 \mathrm{~V}$ (vs RHE), the system had a strong cathodic response, suggesting the existence of oxide species in $\mathrm{CuO}_{\mathrm{x}}$. To identify species of such oxides, as depicted in Supplementary Fig. $3 b$, the CV scanning in a cathodic direction showed that in the first cycle (green line), a noticeable reduction peak which was preceded by a slight oxidation peak could be corresponding to a reduction from $\mathrm{Cu}^{+}$to $\mathrm{Cu}$, suggesting the oxidized copper atoms in our catalyst were nearly cuprous ${ }^{38}$. In the second cycle of the CV measurement (indicated in red), the original slight oxidation peak grew clearer as shown in the inset of Supplementary Fig. 3b. This growth supported the idea that our catalysts contained $\mathrm{Cu}^{+}$ions, since the following reduction phenomenon also occurred and represented the reduction of $\mathrm{Cu}^{+}$to $\mathrm{Cu}$.

To further confirm the chemical composition, X-ray absorption spectroscopy (XAS) of $\mathrm{Cu}$ K-edge for the $\mathrm{CuO}_{\mathrm{x}}$ was conducted (Fig. If and Supplementary Fig. 4). As depicted in
Fig. 1f, the normalized 1st derivative of X-ray absorption near edge structure (XANES) of $\mathrm{CuO}_{\mathrm{x}}$ and references suggested that no detectable $\mathrm{Cu}$ (II) species existed in the as-prepared $\mathrm{CuO}_{\mathrm{x}}{ }^{39}$. On the other hand, a strong peak overlapping that of $\mathrm{Cu}_{2} \mathrm{O}$ at $\sim 8980 \mathrm{eV}$ indicated the presence of $\mathrm{Cu}(\mathrm{I})$ species in the $\mathrm{CuO}_{\mathrm{x}}$ catalyst. Notably, a slight difference between the normalized absorbance at $8981 \mathrm{eV}$ of $\mathrm{CuO}_{\mathrm{x}}$ and that of $\mathrm{Cu}_{2} \mathrm{O}$ might be attributed to a couple of reasons, such as a dilution effect from metallic $\mathrm{Cu}$ species and the catalysts' nanoscale ${ }^{25}$. Wavelet transform was employed to clarify the coordination environment near by the $\mathrm{Cu}$ atom and demonstrate the atomic dispersion of $\mathrm{Cu}$ in the $\mathrm{CuO}_{\mathrm{x}}$ sample. As shown in Fig. 1g, a strong wavelet transform signal focused at $7.4 \AA^{-1}$ derived from $\mathrm{Cu}-\mathrm{O}$ contribution can be observed, while another stronger signal focused at $8.8 \AA^{-1}$ can be attributed to a contribution of $\mathrm{Cu}-\mathrm{Cu}$. The Fourier-transformed $\mathrm{k}^{3}$-weighted spectra of $\mathrm{CuO}_{\mathrm{x}}$ and corresponding references reveal the characteristic peaks at $2.3 \AA$, which correspond to the $\mathrm{Cu}-\mathrm{Cu}$ scattering, implying the existence of metallic $\mathrm{Cu}$ (Fig. 1h). Note that a significant Fouriertransformed peak at $1.6 \AA$ can be referred to the scattering path of 
a
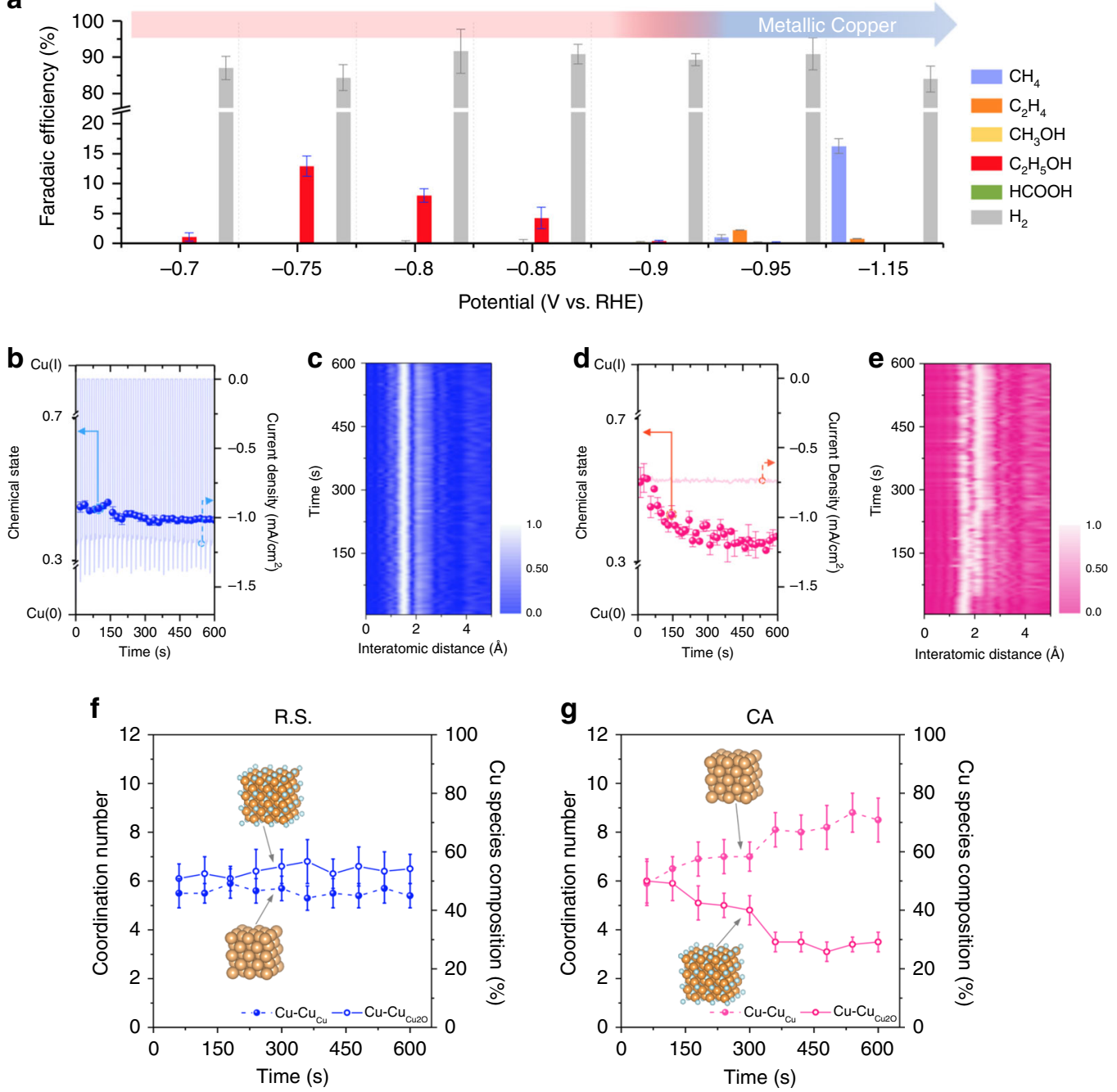

Fig. 2 Operando time-resolved XAS characterization. a Potential dependence of $\mathrm{CO}_{2} \mathrm{RR}$ product selectivity on the $\mathrm{CuO}_{x}$ in $0.5 \mathrm{M} \mathrm{CO}$-saturated $\mathrm{KHCO}_{3}$ under the employment of redox shuttle. The error bars represented standard deviations based on three individual measurements. $\mathbf{b}$ Time-resolved variations using Redox Shuttle (R.S.) of $\mathrm{Cu}$ species in $\mathrm{CuO}_{x}$ and the corresponding electrochemical responses during $\mathrm{CO}_{2} \mathrm{RR}$ at $-0.75 \mathrm{~V}$ and $\mathbf{c}$ the corresponding time-resolved EXAFS spectra without phase-correction of $\mathrm{CuO}_{x}$ under $\mathrm{CO}_{2} \mathrm{RR}$. d Time-resolved variations using chronoamperometry (CA) of $\mathrm{Cu}$ species in $\mathrm{CuO}_{x}$ and the corresponding electrochemical responses during $\mathrm{CO}_{2} \mathrm{RR}$ at $-0.75 \mathrm{~V}$ and $\mathbf{e}$ the corresponding time-resolved EXAFS spectra without phase-correction of $\mathrm{CuO}_{x}$ under $\mathrm{CO}_{2} \mathrm{RR}$. The spectra were depicted in a $2 \mathrm{D}$ contour plot with interatomic distance $(\AA)$ on $x$-axis and with time (sec) on $y$-axis, while normalized Fourier transform magnitude served as corresponding intensity. Quantification of time-resolved chemical composition information extracted from operando Quick $\mathrm{Cu} X A S$ for $\mathrm{CuO}_{x}$ under $\mathrm{eCO}_{2} \mathrm{RR}$ using redox shuttle (f) and conventional chronoamperometry (g). Each error bar indicated an estimated standard deviation based on the curve fitting of EXAFS spectra. Both cathodic potentials were $-0.75 \mathrm{~V}$ and electrolyte was $0.5 \mathrm{M} \mathrm{CO}_{2}$-saturated $\mathrm{KHCO}_{3}$.

$\mathrm{Cu}-\mathrm{O}$, which implied the presence of the $\mathrm{Cu}$ oxide with a similar nature to that of $\mathrm{Cu}_{2} \mathrm{O}$. The wavelet transform contour plot of $\mathrm{CuO}_{\mathrm{x}}$ also further clarified the neighboring environment around $\mathrm{Cu}$, which is consistent with all observations above and indicated the fact that the copper species in the as-prepared $\mathrm{CuO}_{\mathrm{x}}$ were nearly of $\mathrm{Cu}$ and $\mathrm{Cu}(\mathrm{I})$.

CO2RR performance evaluation. To realize the steady chemical state of the as-prepared $\mathrm{CuO}_{\mathrm{x}}$ and clarify the real dominated factor in $\mathrm{CO}_{2}$ reduction electrocatalysis, we adopted the method of switching potential (redox shuttle; R.S. hereafter). Specifically, we applied a constant anodic potential $(0.5 \mathrm{~V})$, which was in light of the above discussion regarding the oxidation of $\mathrm{CuO}_{\mathrm{x}}$, and various cathodic potentials (from -0.7 to $-1.15 \mathrm{~V}$ ). The time interval of each anodic and cathodic potential cycle was set for $10 \mathrm{~s}$ (see Supplementary Fig. 6 for the potential map of R.S.). As stated above, the technique provides the electrocatalytic materials with a cycle of oxidation and reduction, thereby having the potential to stabilize the chemical nature of materials. Figure $2 \mathrm{a}$ exhibited the overall $\mathrm{CO}_{2} \mathrm{RR}$ performance of the as-prepared $\mathrm{CuO}_{\mathrm{x}}$ catalyst. Surprisingly, until $-0.9 \mathrm{~V}$, the $\mathrm{C}_{2} \mathrm{H}_{5} \mathrm{OH}$ molecule was the only identified $\mathrm{CO}_{2} \mathrm{RR}$ product in our system while the rest product was hydrogen gas generating from proton reduction, and the corresponding F.E. (Faradaic Efficiency) reach a maximum value of $\sim 12.9 \% @-0.75 \mathrm{~V}$. With increasing the cathodic potential through the redox shuttle, the F.E. of ethanol gently declined. Note that the ethanol was still the only product from $\mathrm{CO}_{2} \mathrm{RR}$. In contrast to the case of redox shuttle, the $\mathrm{CO}_{2}$ reduction product through a conventional chronoamperometry (CA hereafter) at the same potential of $-0.75 \mathrm{~V}$ was carbon monoxide (Supplementary Fig. 5), which was characteristic of a copper-like behavior with the only product of $\mathrm{CO}$ from $\mathrm{CO}_{2} \mathrm{RR}$ at such potential ${ }^{1,37}$. The $\mathrm{CuO}_{\mathrm{x}}$ catalyst in present study gave a 
copper-like $\mathrm{CO}_{2} \mathrm{RR}$ performance once applying a higher cathodic potentials (higher than $-0.95 \mathrm{~V}$ ) where the dominant $\mathrm{CO}_{2} \mathrm{RR}$ product was $\mathrm{CH}_{4}$. We could say that even though the increasing potential would bring a decline in F.E. toward ethanol, the single product from $\mathrm{CO}_{2} \mathrm{RR}$ still could be realized without presence of other common $\mathrm{CO}_{2} \mathrm{RR}$ products, such as $\mathrm{C}_{2} \mathrm{H}_{4}, \mathrm{CO}$, and $\mathrm{CH}_{4}$. This finding further validates the fact that the redox shuttle can achieve the desired single selectivity of $\mathrm{CO}_{2} \mathrm{RR}$. Note that we kept anodic potential at $0.5 \mathrm{~V}$ (vs RHE), referred to the oxidation potential of as-prepared $\mathrm{CuO}_{\mathrm{x}}$ (as revealed in Supplementary Fig. 3 ), and varied the cathodic potentials from -0.7 to $-1.15 \mathrm{~V}$ (vs RHE). Anodic and cathodic potentials were switched in an interval of $10 \mathrm{~s}$ (Supplementary Fig. 6). Apparently, it seems that a large cathodic potential was able to result in significant increasing the current density of $\mathrm{CO}_{2} \mathrm{RR}$. Nevertheless, the large cathodic potential was failed to achieve a highly selective $\mathrm{CO}_{2} \mathrm{RR}$ production since that was going to cause a remarkably generation of metallic $\mathrm{Cu}^{0}$ (vide infra). As indicated by the $\mathrm{CV}$ results (Supplementary Fig. 7 and Supplementary Note 1), the oxidation variations of $\mathrm{Cu}$ species between applied cathodic potentials were relatively subtle through using R.S. and therefore highly suggested the technique enabled the composition of $\mathrm{Cu}$ species in the $\mathrm{CuO}_{\mathrm{x}}$ to be well preserved. Interestingly, it is well known that the formation of $\mathrm{C}_{2} \mathrm{H}_{4}$ and $\mathrm{C}_{2} \mathrm{H}_{5} \mathrm{OH}$ may share the same path way of $\mathrm{CO}_{2} \mathrm{RR}$ through a hydroxyl containing intermediates ${ }^{40-42}$. As a result, more detail analyses in following sections are essential to address why $\mathrm{C}_{2} \mathrm{H}_{5} \mathrm{OH}$ is the favorable product rather than $\mathrm{C}_{2} \mathrm{H}_{4}$ in our system.

Operando XAS characterization. To assess the chemical composition of the $\mathrm{CuO}_{\mathrm{x}}$ under $\mathrm{CO}_{2} \mathrm{RR}$, operando XAS was performed, due to its capability to probe the chemical composition of the catalysts under realistic reaction conditions ${ }^{26,43-45}$. As we mentioned above, conventional XAS only offers the information which is referred to a steady condition because of time requirement in spectrum acquirement (typically several tens mins). Thus, it inaccessibly provides a convincing time-resolved information for an electrochemical system where the reactions are typically being steady on a timescale of seconds or few minutes ${ }^{46}$. With the aim of addressing this timescale mismatch, the operando time-resolved X-ray absorption spectroscopy (operando TR-XAS) with a sub-second time-resolution can be reached by equipping a continuously oscillating crystal on a monochromator ${ }^{47}$. Operando time-resolved-XANES spectra for $\mathrm{CuO}_{\mathrm{x}}$ during $\mathrm{CO}_{2} \mathrm{RR}$ at $-0.75 \mathrm{~V}$ (vs RHE) using R.S. and those of using CA were displayed in Supplementary Figs. 8 and 9, respectively. A linear model developed by Vitova et al. ${ }^{48}$ was utilized to extract the pristine and time-resolved compositional information from acquired XANES spectra. As shown in Supplementary Fig. 10, the result suggested that the composition of the pristine $\mathrm{CuO}_{\mathrm{x}}$ was of equal $\mathrm{Cu}(\mathrm{I})$ and $\mathrm{Cu}$. This not only supported again our previous characterization that $\mathrm{Cu}(\mathrm{I})$ and $\mathrm{Cu}$ coexisted in the $\mathrm{CuO}_{\mathrm{x}}$ (Fig. 1c-h), but also proved the feasibility of the linear model to quantitatively analyze the composition of $\mathrm{Cu}$ species, as Vitova et al. suggested. In this regard, we used the linear model to extract the chemical nature information of $\mathrm{CuO}_{\mathrm{x}}$ from the operando time-resolved-XANES spectra. Extracted time-resolved chemical composition information combined with the electrochemical responses was shown in Fig. 2 (2b for R.S. and 2d for CA) and in Supplementary Fig. 11 (the magnified portion of Fig. $2 b$ by which one can track the footprint of XAS acquisition under the R.S. working condition). During the $\mathrm{CO}_{2}$ RR, R.S. restricted the chemical composition of $\mathrm{CuO}_{\mathrm{x}}$ in around a composition of half $\mathrm{Cu}$ and half $\mathrm{Cu}(\mathrm{I})$, while the $\mathrm{CA}$ transformed the chemical
Table 1 Operando EXAFS fitting parameter for the $\mathrm{CuO}_{\mathrm{x}}$ at $-0.75 \mathrm{~V}$ under $\mathrm{CO}_{2} \mathrm{RR}$ using redox shuttle approach.

\begin{tabular}{|c|c|c|c|c|}
\hline \multirow{2}{*}{$\begin{array}{l}\text { Sample } \\
\text { Time (s) }\end{array}$} & \multicolumn{2}{|c|}{$\mathrm{Cu}-\mathrm{Cu}_{\mathrm{Cu} 2 \mathrm{O}}$} & \multicolumn{2}{|c|}{$\mathrm{Cu}-\mathrm{Cu}_{\mathrm{Cu}}$} \\
\hline & C.N. & $R(\AA)$ & C.N. & $R(\AA)$ \\
\hline 60 & $6.1(6)$ & $3.02(2)$ & $5.5(6)$ & $2.45(3)$ \\
\hline 120 & $6.3(7)$ & $3.03(3)$ & $5.5(4)$ & $2.43(2)$ \\
\hline 180 & $6.1(5)$ & $3.03(2)$ & $5.9(6)$ & $2.45(3)$ \\
\hline 240 & $6.4(9)$ & 3.02 (3) & $5.6(5)$ & $2.45(3)$ \\
\hline 300 & $6.6(7)$ & $3.00(3)$ & $5.7(5)$ & $2.45(2)$ \\
\hline 360 & $6.8(9)$ & 3.04 (3) & $5.3(5)$ & $2.44(2)$ \\
\hline 420 & $6.3(6)$ & $3.00(3)$ & $5.5(6)$ & $2.45(3)$ \\
\hline 480 & $6.6(8)$ & 3.02 (1) & $5.4(5)$ & $2.45(1)$ \\
\hline 540 & $6.4(8)$ & $3.02(3)$ & $5.7(6)$ & $2.45(3)$ \\
\hline 600 & $6.5(6)$ & $3.02(3)$ & $5.4(5)$ & $2.45(2)$ \\
\hline
\end{tabular}

Uncertainties in the last digit are given in parentheses.

\begin{tabular}{|c|c|c|c|c|}
\hline \multirow[b]{2}{*}{ Time (s) } & \multicolumn{2}{|c|}{$\mathrm{Cu}-\mathrm{Cu}_{\mathrm{Cu} 2 \mathrm{O}}$} & \multicolumn{2}{|c|}{$\mathrm{Cu}-\mathrm{Cu}_{\mathrm{Cu}}$} \\
\hline & C.N. & $R(\AA)$ & C.N. & $R(\AA)$ \\
\hline 60 & $6.9(9)$ & $2.88(4)$ & $5.9(9)$ & $2.43(4)$ \\
\hline 120 & $5.9(7)$ & $2.98(3)$ & $6.5(5)$ & $2.43(2)$ \\
\hline 180 & $5.1(7)$ & $2.92(3)$ & $6.9(7)$ & 2.47 (3) \\
\hline 240 & $5.0(5)$ & $2.95(2)$ & $7.0(7)$ & 2.49 (2) \\
\hline 300 & $4.8(6)$ & $2.91(3)$ & $7.0(6)$ & $2.41(2)$ \\
\hline 360 & $3.5(4)$ & $2.90(2)$ & $8.1(7)$ & $2.42(2)$ \\
\hline 420 & $3.5(4)$ & $2.93(3)$ & $8.0(7)$ & $2.45(2)$ \\
\hline 480 & $3.1(4)$ & $2.91(3)$ & $8.2(9)$ & $2.44(3)$ \\
\hline 540 & $3.4(3)$ & $2.96(2)$ & $8.8(8)$ & $2.46(2)$ \\
\hline 600 & $3.5(4)$ & 2.89 (3) & $8.5(9)$ & $2.46(3)$ \\
\hline
\end{tabular}

Uncertainties in the last digit are given in parentheses.

composition of $\mathrm{CuO}_{\mathrm{x}}$ into that $\mathrm{Cu}$-dominated. Following the 1hour reaction time, XANES spectrum of the $\mathrm{CuO}_{x}$ after the $\mathrm{CO}_{2}$ RR using R.S. remained nearly unchanged, further indicative of R.S. having the ability to preserve the chemical composition. On the other hand, that of the $\mathrm{CuO}_{\mathrm{x}}$ after the electrolysis using CA clearly showed an electrochemical reduction toward metallic $\mathrm{Cu}$ (Supplementary Fig. 10).

As shown in Fig. 2c, e, operando time-resolved EXAFS verified that the intensity of bond pairs regarding $\mathrm{Cu}-\mathrm{O}$ at $1.6 \AA$ and $\mathrm{Cu}-\mathrm{Cu}$ at $2.3 \AA$ stayed highly stable under the employment of R.S., whereas the intensity under the case of using CA showed a decline at $1.6 \AA$ and an increase at $2.3 \AA$ that could be corresponded to a transformation from $\mathrm{Cu}_{2} \mathrm{O}$ to metallic $\mathrm{Cu}^{0}$. To further quantify such chemical composition information from operando EXAFS, we obtained the $\mathrm{Cu}-\mathrm{Cu}$ path from both $\mathrm{Cu}_{2} \mathrm{O}$ $\left(\mathrm{Cu}-\mathrm{Cu}_{(\mathrm{Cu} 2 \mathrm{O})}\right)$ and metallic $\mathrm{Cu}\left(\mathrm{Cu}-\mathrm{Cu}_{(\mathrm{Cu})}\right)$ extracted by a standard fitting procedure (detailed results shown in Tables 1-2 and Supplementary Figs. 12-31). We note here that in order to have quality spectra for EXAFAS fitting, the related XAS acquisition time was extended from 5 to $60 \mathrm{~s}$. While the time resolution could not match that of seconds (Fig. 2b-e), the minutes-resolved EXAFS fitting results were also in line with those seconds-resolved (see below). The quantification was displayed in terms of coordination numbers and, more straightforward, in terms of the percentage of both $\mathrm{Cu}(0)$ and 
a

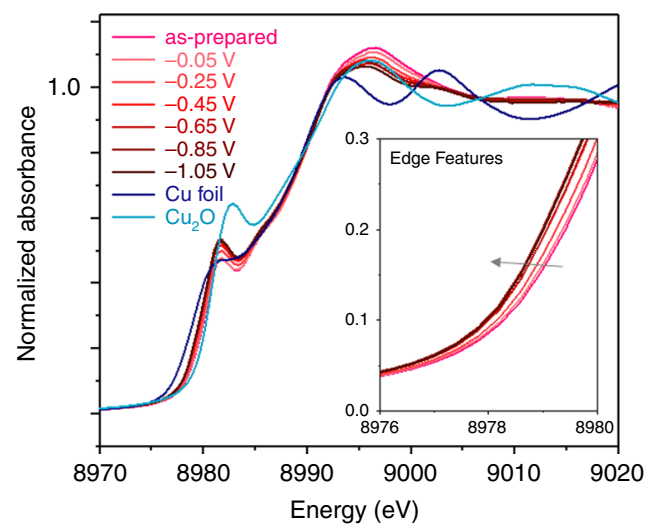

d

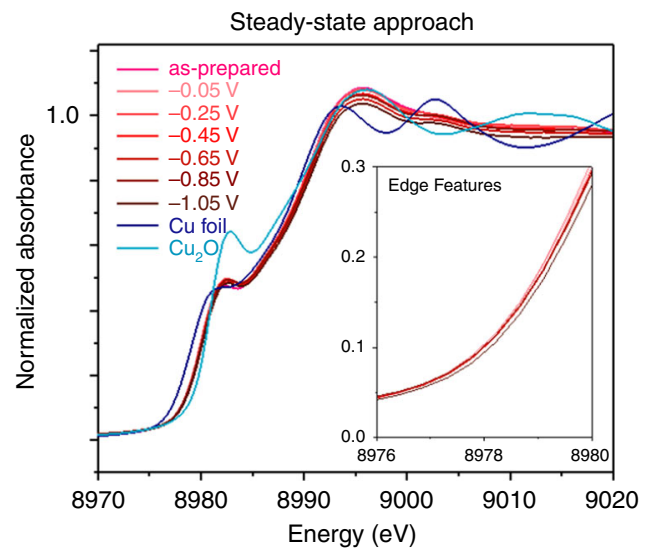

b

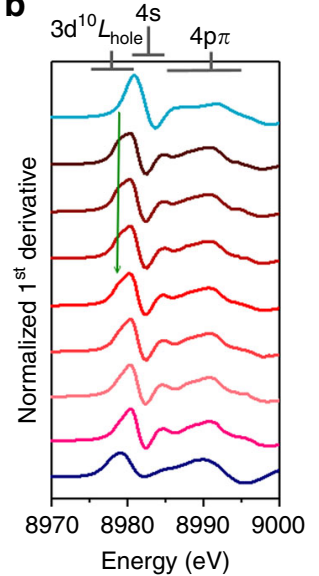

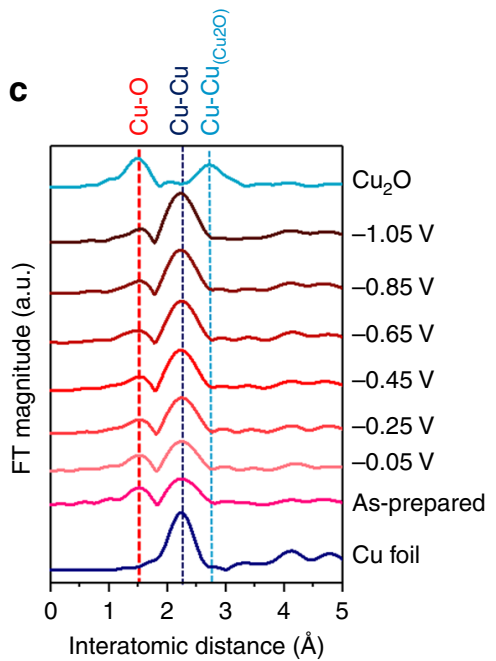

e

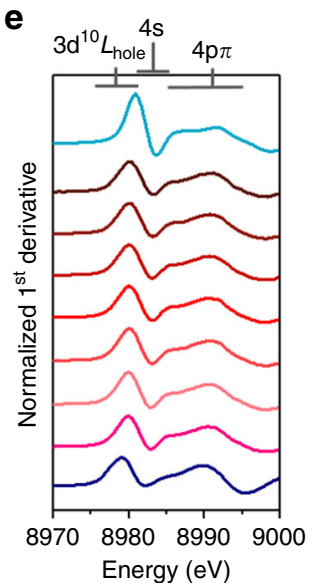

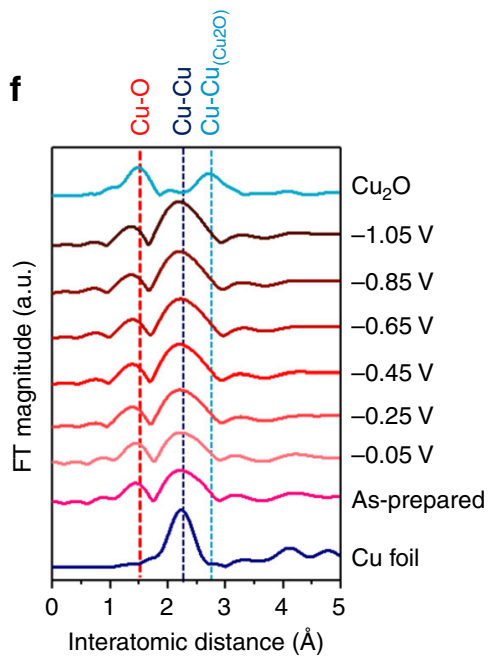

Fig. 3 Conventional operando XAS characterization. a Potential dependence of operando $\mathrm{Cu} \mathrm{K}$ edge $\mathrm{XANES}$ spectra without phase-correction of the $\mathrm{CuO}_{\times}$ under $\mathrm{CO}_{2} \mathrm{RR}$ in $0.5 \mathrm{M} \mathrm{CO}_{2}$-saturated $\mathrm{KHCO}_{3}$ using chronoamperometry (CA) and the corresponding 1st derivative spectra (b). c Potential dependence of operando EXAFS spectra of the $\mathrm{CuO}_{x}$ under eCO${ }_{2} \mathrm{RR}$ in $0.5 \mathrm{M} \mathrm{CO}_{2}$-saturated $\mathrm{KHCO}_{3}$ using CA. d Potential dependence of operando $\mathrm{Cu} \mathrm{K}$ edge $\mathrm{XANES}$ spectra without phase-correction of the $\mathrm{CuO}_{x}$ under $\mathrm{CO}_{2} \mathrm{RR}$ in $0.5 \mathrm{M} \mathrm{CO}_{2}$-saturated $\mathrm{KHCO}_{3}$ using R.S. and the corresponding 1st derivative spectra (e). $\mathbf{f}$ Potential dependence of operando EXAFS spectra of the $\mathrm{CuO}_{x}$ under $\mathrm{eCO}_{2} \mathrm{RR}$ in $0.5 \mathrm{M} \mathrm{CO}_{2}$-saturated $\mathrm{KHCO}_{3}$ using R.S.

$\mathrm{Cu}(\mathrm{I})$ according to Eqs. (1) and (2):

$$
\begin{aligned}
& \frac{C N_{(\text {experimental } \mathrm{Cu}-\mathrm{Cu} @ 2.5 \AA)}}{C N_{(\text {theorectical metallic } \mathrm{Cu})}} \times 100 \%=\mathrm{Cu}(0) \operatorname{composition}(\%) \\
& \frac{C N_{(\text {experimental } \mathrm{Cu}-\mathrm{Cu} @ 3.0 \AA)}}{C N_{(\text {theorectical Cu2o })}} \times 100 \%=C u(I) \operatorname{composition}(\%)
\end{aligned}
$$

where $\mathrm{CN}_{(\text {experimental } \mathrm{Cu}-\mathrm{Cu} @ 2.5 \AA \text { ) }}$ and $\mathrm{CN}_{(\text {experimental } \mathrm{Cu}-\mathrm{Cu} @ 3.0 \AA)}$ represent the coordination numbers $(\mathrm{CNs})$ of the $\mathrm{Cu}-\mathrm{Cu}$ path at $2.5 \AA$ and $3.0 \AA$, respectively. $\mathrm{CN}_{(\text {theoretical metallic } \mathrm{Cu})}$ and $\mathrm{CN}_{\text {(theoretical Cu2O) }}$ are equal to those of metallic $\mathrm{Cu}$ and $\mathrm{Cu}_{2} \mathrm{O}$, namely 12 . As depicted in Fig. $2 \mathrm{f}$, g, time-resolved fitting results fairly agreed with both analyses of XANES and EXAFS. Using R. S., the $\mathrm{CNs}$ of $\mathrm{Cu}(\mathrm{I})$ and $\mathrm{Cu}(0)$ in the as-prepared $\mathrm{CuO}_{\mathrm{x}}$ stayed relatively steady during $\mathrm{CO}_{2} \mathrm{RR}$ (Fig. 2f). By contrast, under the employment of $\mathrm{CA}$, the $\mathrm{CNs}$ of $\mathrm{Cu}(\mathrm{I})$ and $\mathrm{Cu}(0)$ in the $\mathrm{CuO}_{\mathrm{x}}$ gradually reduced and increased, respectively, suggesting the electrochemical reduction of the $\mathrm{CuO}_{\mathrm{x}}$ (Fig. 2g). Consequently, the results of time-resolved operando XAS proved that under $\mathrm{CO}_{2} \mathrm{RR}$, the chemical composition of $\mathrm{CuO}_{\mathrm{x}}$ could remain in a steady state of half-and-half $\mathrm{Cu}$ and $\mathrm{Cu}(\mathrm{I})$ through using R.S.
By contrast, under the employment of CA, the chemical composition of $\mathrm{CuO}_{\mathrm{x}}$ continued a downward trend toward $\mathrm{Cu}(0)$. A similar result as illustrated in Fig. 3 was also revealed by the conventional XAS, showing a significant reduction of $\mathrm{Cu}^{+}$to generate metallic $\mathrm{Cu}^{0}$. XANES data elucidated as a cathodic potential was applied from -0.05 to $-1.25 \mathrm{~V}$ (Fig. 3a, b). The XANES features as illustrated in Fig. $3 \mathrm{~b}$ were denoted as three distinct peak-like structures, while no remarkable pre-edge feature that caused by a dipole transition from $1 s$ to the mixing states of $4 p$ and $3 d$ could be visible and suggested a centrosymmetry nature of copper ${ }^{37,49}$. An additional small feature of the excitation in the $3 \mathrm{~d}^{10} \mathrm{~L}_{\text {hole }}$ state at a lower energy region (as indicated by green arrow) gradually intensifies with increasing cathodic voltage, this indicates the formation of metallic $\mathrm{Cu}$ (Fig. 3b). Furthermore, the shifts in the edge position could conclude the chemical states in $\mathrm{CuO}_{\mathrm{x}}$ were reduced into copperlike and the content of metallic $\mathrm{Cu}(0)$ species in the $\mathrm{CuO}_{\mathrm{x}}$ evidently increased. Consistent with XANES spectra, the analysis of extended X-ray absorption fine structure (EXAFS) revealed that as an applied cathodic potential increased, the metallic $\mathrm{Cu}-\mathrm{Cu}$ bond pair at $2.3 \AA$, matching a standard metallic $\mathrm{Cu}$, intensified significantly (Fig. 3c). Worth noting is that like cases 
in literature ${ }^{39}$, the as-prepared $\mathrm{CuO}_{\mathrm{x}}$ exhibited a resistance to electrochemical reduction, as the intensity of a $\mathrm{Cu}-\mathrm{O}$ bond pair at $\sim 1.6 \AA$, referring to a $\mathrm{Cu}_{2} \mathrm{O}$ standard, did not entirely disappear even under a cathodic environment. Despite having this resistance to the electrochemical reduction, however, the asprepared $\mathrm{CuO}_{\mathrm{x}}$ could not remain its initial chemical nature under $\mathrm{CO}_{2} \mathrm{RR}$ when the CA was adopted. This observation can refer to the fact that the catalytic sites and the chemical states can fail to reach a steady situation under the conventional chronoamperometry. These results also can explicate the finding from numerous reports that the products profile of $\mathrm{CO}_{2} \mathrm{RR}$ are commonly characteristic of a mixture nature.

To extend the investigation further, we also performed conventional operando XAS analyses for the $\mathrm{CuO}_{\mathrm{x}}$ under $\mathrm{CO}_{2} \mathrm{RR}$ using R.S. in various potentials (Fig. $3 \mathrm{~d}-\mathrm{f}$ ). Only slight variations on XAS results across the various applied potentials, the chemical composition of $\mathrm{CuO}_{\mathrm{x}}$ could remain in a steady condition of the composition of $\mathrm{Cu}$ and $\mathrm{Cu}(\mathrm{I})$ through using R.S. as illustrated in Fig. 3d, e. Note that, as compared with those of Fig. 3b, no additional feature of the excitation in the $3 \mathrm{~d}^{10} \mathrm{~L}_{\text {hole }}$ state at a lower energy region can be found with increasing cathodic voltage, this further indicates the chemical nature of $\mathrm{CuO}_{\mathrm{x}}$ can reach steadystate under $\mathrm{CO}_{2} \mathrm{RR}$ using R.S. (Fig. 3e). In the case of operando EXAFS spectra, the final condition from various applied potentials were similar except for the situations in high cathodic potentials $(<-0.95 \mathrm{~V}$ vs $\mathrm{RHE})$. This finding corroborated the observation of potential-dependent product profiles in Fig. 2a, in which the $\mathrm{CO}_{2} \mathrm{RR}$ products have become a metallic copper-like profile with a mixed feature. Therefore, these results became solid evidence to conclude the existence of the steady composition of $\mathrm{Cu}$ species under $\mathrm{CO}_{2} \mathrm{RR}$ using R.S. Aside from spectroscopic analysis, the post electron microscopy analysis also supported the validation of R.S. As shown in Supplementary Fig. 32, the TEM image of $\mathrm{CuO}_{\mathrm{x}}$ after a $6-\mathrm{h} \mathrm{CO}_{2} \mathrm{RR}$ electrolysis at $-0.75 \mathrm{~V}$ using $\mathrm{R}$. $\mathrm{S}$. demonstrated that the morphology of the $\mathrm{CuO}_{\mathrm{x}}$ was similar to those before the electrolysis (Fig. 1d). This consistence fairly helped rule out the possibility that the observed $\mathrm{CO}_{2} \mathrm{RR}$ performance in the present study was brought by morphology change ${ }^{37}$. Meanwhile, the HR-TEM analysis, as well as related SAED, of the post-catalysts in Supplementary Fig. 33 also confirmed the chemical nature of the $\mathrm{CuO}_{\mathrm{x}}$ was the same as the as-prepared catalyst (Fig. 1e). Furthermore, in terms of electrochemical stability, we also evaluated the electrochemical active surface area (ECSA) of $\mathrm{CuO}_{\mathrm{x}}$ before and after the $\mathrm{CO}_{2} \mathrm{RR}$ electrolysis. The double layer capacitance $\left(C_{\mathrm{dl}}\right)$ was used for the assessment, since it is directly proportional to the ECSA of materials ${ }^{50,51}$. Using a cyclic voltammetry $(\mathrm{CV})$ method, the $C_{\mathrm{dl}}$ values of $\mathrm{CuO}_{\mathrm{x}}$ before and after the electrolysis were 77.27 and $76.60 \mu \mathrm{F} \mathrm{cm}^{-2}$, respectively (Supplementary Figs. 34 and 35 ). The result of nearly the same $C_{\mathrm{dl}}$ values reflected the fairly stable ECSA of $\mathrm{CuO}_{\mathrm{x}}$ after the electrolysis and highly suggested the stability of using R.S. Altogether, results of the operando XAS analyses, the electron microscopy analyses, and electrochemical studies convincingly proved the validation of R.S. as a steady-state approach.

Through operando TR-XAS analyses, we correlated the chemical nature of $\mathrm{CuO}_{\mathrm{x}}$ with its unique selectivity toward asymmetric $\mathrm{C}_{2} \mathrm{H}_{5} \mathrm{OH}$ molecules, which has evidently concluded a paramount role played by the composition of the $\mathrm{Cu}-\mathrm{Cu}(\mathrm{I})$ ensemble. Moreover, the preceding analyses also revealed that different $\mathrm{CO}_{2} \mathrm{RR}$ products may result from catalytic surfaces with different compositions of $\mathrm{Cu}$ and $\mathrm{Cu}(\mathrm{I})$; a $\mathrm{Cu}$-dominated surface synthesized $\mathrm{CO}$, while the surface with halves of $\mathrm{Cu}$ and $\mathrm{Cu}(\mathrm{I})$ gave rise to ethanol (Supplementary Fig. 10). This rather suggests a delicate $\mathrm{Cu}(\mathrm{I}) / \mathrm{Cu}(0)$ interface is the likely active center for $\mathrm{CO}_{2}$ to asymmetric products and motivates future work regarding such interfacial engineering. Analogous interfacial engineering strategies have been applied to enhance product selectivity in electrochemical reaction systems $s^{52,53}$. The study by Feng et al., for example, has demonstrated a linear correlation between the boundary densities within their as-prepared $\mathrm{Cu}$ nanoparticles and the corresponding catalytic behavior of reducing $\mathrm{CO}$ to multicarbon products, i.e., ethanol and acetate ${ }^{54}$. Furthermore, using scanning electrochemical cell microscopy (SECCM), Mariano and coworkers provided a submicrometer-resolved study on gold films ${ }^{55}$. The study with such spatial resolution clearly demonstrated that the electrocatalytic activity of a gold film for $\mathrm{CO}_{2} \mathrm{RR}$ depends on the grain boundary types and densities on the film.

Theoretical understanding of the CO2RR selectivity. As follows, we make an attempt to elucidate the unique selectivity in our reaction system thorough theoretical computation. By using density functional theory (DFT) calculations, we further evaluated the stability of oxygen-vacancy generation/removal with various compositions of $\mathrm{Cu}$ and $\mathrm{Cu}(\mathrm{I})$ at the top layer of $\mathrm{Cu}_{2} \mathrm{O}$. All details regarding the structural simulation are addressed in Methods, while the model coordinates are listed in Supplementary Table 1. Such a geometric stability during the oxygen removal process can potentially facilitate the regeneration of the acting-catalytic environment by the redox-shuttle approach. These structural simulation results demonstrated that the equal numbers of $\mathrm{Cu}$ and $\mathrm{Cu}(\mathrm{I})$ on the top layer could provide an ideal environment to host the $\mathrm{C}-\mathrm{C}$ bond formation intermediate (OCCO) (Supplementary Figs. 36 and 37). All studies in following parts, therefore, will focus on the surface composed of the equal numbers of $\mathrm{Cu}$ and $\mathrm{Cu}(\mathrm{I})$ for subsequent modeling (defined it as a $\mathrm{Cu}-\mathrm{Cu}(\mathrm{I})$ ensemble). Afterwards, we characterized C-C coupling behavior on the $\mathrm{Cu}-\mathrm{Cu}(\mathrm{I})$ ensemble, and the configurational results-calculated absorption energy and geometrically optimized structures of absorbed CO molecules at the gas-solid interface - were shown in Supplementary Fig. 37. The ensemble configured dimerized CO molecules to an asymmetric "end-side" configuration; a CO molecule was absorbed in the side-on direction and coupled with an end-on $\mathrm{CO}$ molecule, which was consistent with previous work ${ }^{56}$.

On the other hand, the explicit water solvation effect has been demonstrated to well achieve a realistic modeling in free energy calculations. As depicted in Fig. 4a, the free energy barriers $\left(\Delta \mathrm{G}^{\ddagger}\right)$ for the $\mathrm{C}-\mathrm{C}$ bond formation under the explicit water solvation indicated the overall OCCO formation on the ensemble was thermodynamically accessible at $0.73 \mathrm{eV}$, as the corresponding reaction free energy $\Delta G$ was $-1.22 \mathrm{eV}$ (for computation details, refer to Supporting Information). Furthermore, Bader charge analysis also suggests that the mixed-valence ensemble constructively stabilize the asymmetrical OCCO intermediate though a favorable electrostatic interaction, in which the highly polar OCCO $(+0.50$ and -1.68 for the positive and negative fragments of $\left(\mathrm{O}_{(1)} \mathrm{C}_{(1)}\right)^{\delta+}\left(\mathrm{C}_{(2)} \mathrm{O}_{(2)}\right)^{\delta-}$, respectively) is stabilized by the presence of $\mathrm{Cu}(0)$ and $\mathrm{Cu}(\mathrm{I})$ on the surface, respectively (Fig. 4b). All computational results demonstrated the potential introduced by the mixed-valence ensemble could produce an asymmetric OCCO intermediate in $\mathrm{CO}_{2} \mathrm{RR}$, which might considerably facilitate the formation of $\mathrm{C}_{2}$ products from $\mathrm{CO}_{2} \mathrm{RR}$.

The plausible mechanistic steps of ethanol formation are computationally explored with considering the various hydrogenated intermediates on the $\mathrm{Cu}-\mathrm{Cu}(\mathrm{I})$ ensemble, being simulated by the mixed-valence $\mathrm{Cu}_{2} \mathrm{O}$ surface model, as highlighted as $1 \mathrm{H}$ to $6 \mathrm{H}$ in Fig. $4 \mathrm{c}$. The calculated electrochemical step started from the hydrogenation step of CCO $(1 \mathrm{H})$, being generated from the dehydration step of the experimental observed $\mathrm{OCCOH}$ intermediate ${ }^{54}$. The relative free energies in respect to the 
a

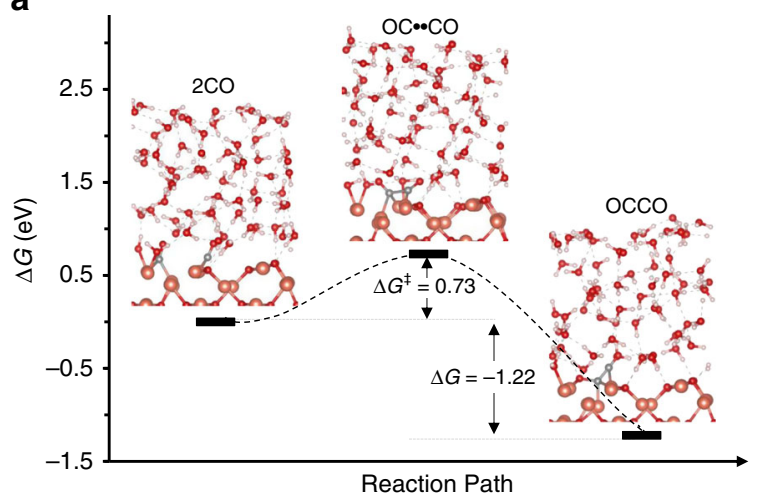

b

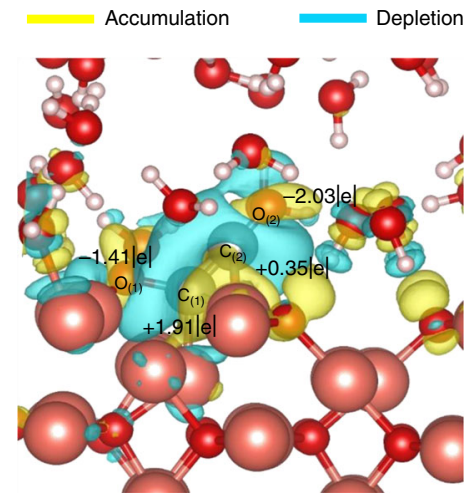

C

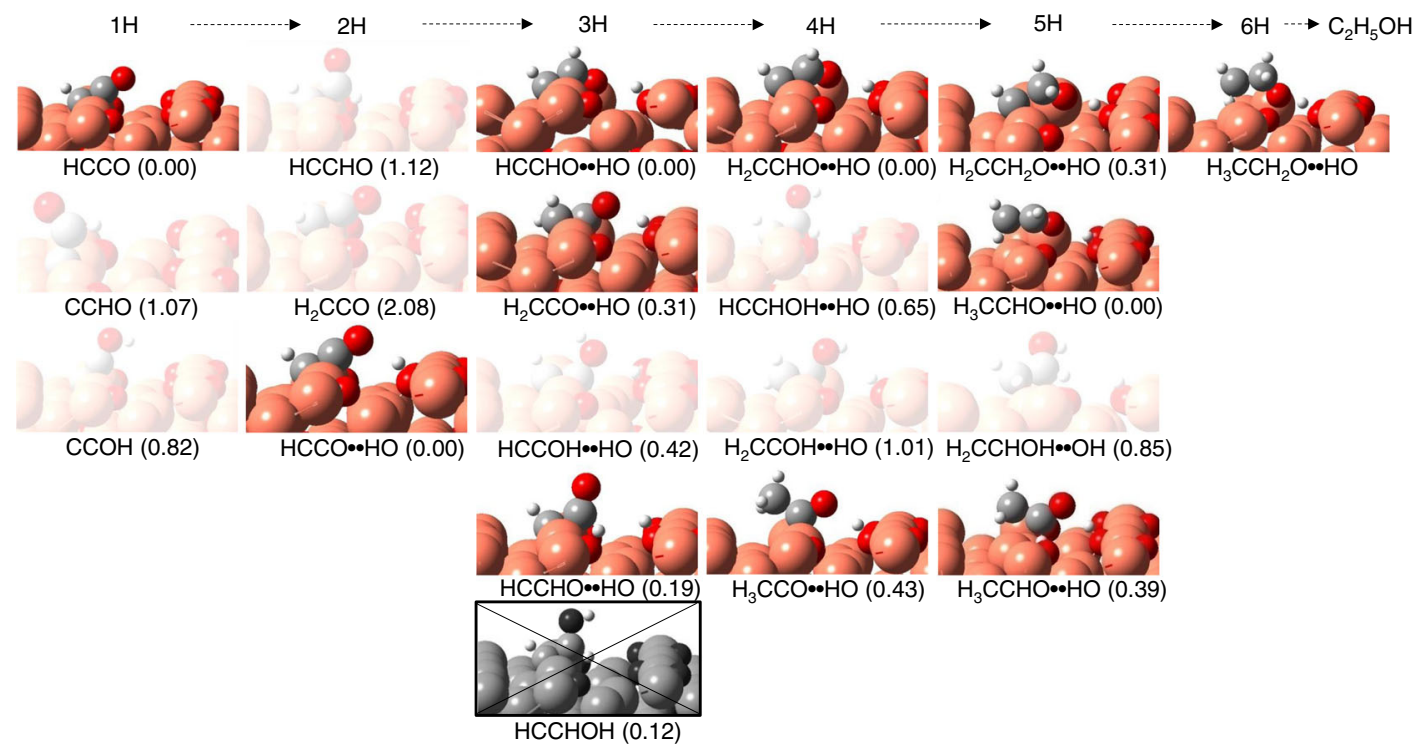

d

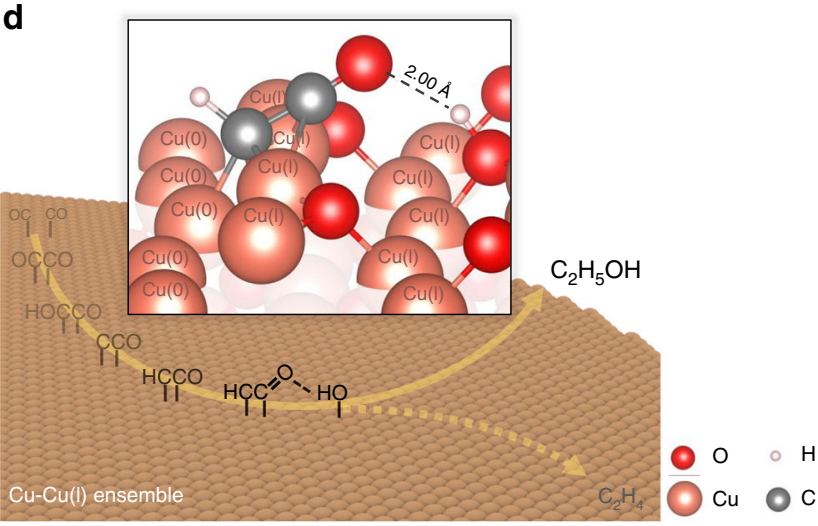

Fig. 4 DFT calculation results and proposed selectivity mechanism scheme. a The profiles of the potential energy surface for the dimerization of CO on $\mathrm{Cu}-\mathrm{Cu}(\mathrm{I})$ ensembles. $\mathbf{b}$ The Bader chargers of the OCCO intermediates. $\mathbf{c}$ The accessible carbonyl-stabilized intermediates on the $\mathrm{Cu}-\mathrm{Cu}(\mathrm{I})$ ensemble. The relative free energy in $\mathrm{eV}$ of each hydrogenation stage is denoted in the parentheses. $\mathbf{d}$ The schematic representations of the determined factor for the selective ethanol synthesis.

minimum geometries (all marked as $0 \mathrm{eV}$ ) at each hydrogenation stage were labeled in Fig. 4c. It should be noted that all of the hydroxyl containing intermediates $\left(\mathrm{CCOH}, \mathrm{HCCOH} \_\mathrm{OH}\right.$, $\mathrm{HCCHOH}+\mathrm{OH}, \mathrm{H}_{2} \mathrm{CCOH} \_\mathrm{OH}$, and $\mathrm{H}_{2} \mathrm{CCHOH}$ found to be less stable by $0.82,0.43,0.65,1.08$, and $0.79 \mathrm{eV}$ than the corresponding minima, respectively, where the presence of hydroxyl groups within the hydrocarbon species could lead to the pathway of ethylene formation via a proton-coupled-electron dehydration process. Although $\mathrm{HCCOH}$ (crossed out in grayscale) was proposed as a necessary intermediate for $\mathrm{C}_{2} \mathrm{H}_{4}$ formation $^{55}$, it became inaccessible due to its unfavorable precursor - HCCHO.

By contrast, $\mathrm{OH}$ species at the boundary of $\mathrm{Cu}-\mathrm{Cu}(\mathrm{I})$ ensemble could play a critical role in facilitating the ethanol formation. Such a mixed-valance region favored the formation of surface hydroxyl given the electron-rich $\mathrm{Cu}$ region enhances the basicity 
of the boundary oxygen sites of $\mathrm{Cu}(\mathrm{I})$ region. Theoretically, $\mathrm{OH}$ species at the $\mathrm{Cu}-\mathrm{Cu}(\mathrm{I})$ boundary was commonly identified along the hydrogenation pathway of $\mathrm{CO}_{2}$ reduction, and that resulted in the attractive electrostatic interactions between surface- $\mathrm{OH}$ dipole and the dipole of carbonyl group of hydrocarbon intermediates. This carbonyl stabilization effect could protect the oxygen end from being protonated as well as occupy the valence electron of carbon to avoid the CC double bond formation. Consequently, managing the boundary oxygen sites during the electrochemical $\mathrm{CO}_{2}$ reduction could be the determined factor of ethanol generation. The unique selectivity toward $\mathrm{C}_{2} \mathrm{H}_{5} \mathrm{OH}$ could be attributed to the fact that the $\mathrm{CuO}_{\mathrm{x}}$ could maintain well balance of $\mathrm{Cu}$ and $\mathrm{Cu}(\mathrm{I})$ during $\mathrm{eCO}_{2} \mathrm{RR}$ using R.S. and offer an asymmetrically OCCO adsorbing site with the subsequent carbonyl group stabilization effect by the $\mathrm{OH}$ groups at the boundary of $\mathrm{Cu}-\mathrm{Cu}(\mathrm{I})$ ensemble, eventually synthesizing an asymmetric oxygenated product (Fig. $4 \mathrm{~d}$ ).

\section{Discussion}

In summary, using redox shuttle manner, the results of product characterization demonstrated that in a wide potential range, the as-prepared $\mathrm{CuO}_{\mathrm{x}}$ exclusively produced $\mathrm{C}_{2} \mathrm{H}_{5} \mathrm{OH}$ over other $\mathrm{CO}_{2} \mathrm{RR}$ products. Using the operando time-resolved XAS, we tracked the evolution of its chemical nature under $\mathrm{CO}_{2} \mathrm{RR}$. Quantitative XANES and EXAFS analyses evidently revealed that the steady chemical composition of the material could be achieved via the usage of the redox shuttle approach, while the employment of conventional chronoamperometry drastically altered the chemical nature of the material. Collectively, a strong correlation between the stabilized ensembles and the corresponding unique selectivity of $\mathrm{CO}_{2} \mathrm{RR}$ products has been established. More importantly, the carbonyl stabilization mechanism by the boundary $\mathrm{OH}$ species was proposed to prevent the protonation of the terminal oxygen sites of hydrocarbons, and such a hedge device produced an oxygenated $\mathrm{CO}_{2} \mathrm{RR}$ product (ethanol in our case) with the unique selectivity. Our studies provided the first empirical real time information, correlating the chemical nature of $\mathrm{Cu}$-based catalysts with their corresponding selectivity toward $\mathrm{CO}_{2} \mathrm{RR}$ products.

\section{Methods}

Chemicals. The copper(I) bromide ( $\mathrm{CuBr}, 98 \%)$, copper(I) chloride $(\mathrm{CuCl}, 99 \%)$, trioctylphosphine (TOPO, 99\%), 1-hexadecylamine (HAD, 90\%), oleylamine (80$90 \%), 1,5$-pentanediol (98\%), and nafion solution (20 wt. \%) were purchased from Acros Organics. The potassium bicarbonate $\left(\mathrm{KHCO}_{3}, 99 \%\right)$ was purchased from Fisher Scientific. The gases $\mathrm{CO}_{2}(99.999 \%)$ and $\mathrm{N}_{2}(99.999 \%)$ were purchased from Shen-Yi Gas Co. These chemicals were used without further purification.

Synthesis for copper nanocubes. The nanocubes were prepared through a polyamine process under an inert atmosphere. $\mathrm{CuBr}(1 \mathrm{mmol})$ and TOPO $(3$ mmol) were firstly dissolved into oleylamine $(15 \mathrm{~mL})$ in a three-neck round-bottom flask. After well mixed, the solution was flushed with $\mathrm{N}_{2}$ for 30 mins to remove the oxygen in the apparatus. Under the inter atmosphere, the solution was heated at $80^{\circ} \mathrm{C}$ for $5 \mathrm{mins}$ and then up to $230^{\circ} \mathrm{C}$ for another $3 \mathrm{~h}$, turning into a reddishbrown clouded solution. Afterwards, the solution was air-cooled to room temperature for purification. The solution was washed with $\mathrm{n}$-hexane $(40 \mathrm{~mL})$ and centrifuged at 8000 r.p.m. for 10 mins three times. The purified nanocubes were stored in $\mathrm{n}$-hexane for the later use.

Synthesis for mixed-valence copper nanomaterials. In all, $20 \mathrm{mg}$ HDA were added into $9 \mathrm{~mL} \mathrm{1,5-pentanediol.} \mathrm{Then,} \mathrm{the} \mathrm{solution} \mathrm{was} \mathrm{preheated} \mathrm{at} 170^{\circ} \mathrm{C}$ for 10 mins. Afterwards, as-prepared copper nanocube solution $(1 \mathrm{~mL})$ was transferred into the solution via one-shot injection. The solution was kept at the temperature for a half hour. Eventually, the solution turned yellow, suggesting the formation of mixed-valence copper nanomaterials. The materials were washed with an ethanolwater mixture in ratio $7: 3$ and centrifuged at 10,000 r.p.m. for $10 \mathrm{~min}$ three times. The purified materials were kept in absolute alcohol for the later use.

Catalyst characterization. The morphology of as synthesized materials was characterized using the transmission electron microscopy (TEM, Hitachi H-760 operated at $80 \mathrm{kV}$ ) and the scanning electron microscopy (SEM, JSM-6700F). The materials' crystal structure was studied by using selected area electron diffraction (SAED) in a high-resolution TEM (HRTEM, JEOL JEM-2100F operated at 200 $\mathrm{kV}$ ). The elemental analysis of the materials was conducted using energy-dispersive $\mathrm{X}$-ray spectroscopy (EDS) inside the HRTEM.

Electrochemical measurements. All electrochemical measurements were carried out using Biologic-VSP instrument and in a three-electrode setup. The working electrode was a glassy carbon electrode $\left(0.782 \mathrm{~cm}^{2}\right)$; the counter electrode, a $\mathrm{Pt}$ wire; the reference electrode, an $\mathrm{Ag} / \mathrm{AgCl}$ electrode (in $3 \mathrm{M} \mathrm{KCl}$ ). The test cell was a home-made electrochemical cell. The cell consisted of two parts, cathode and anode compartments. The working electrode and reference electrode were placed into the cathode compartment, and the counter was in the anode compartment. Both compartments were separated by an anion exchange membrane (Fumasep FAA-3-PK-130, FUMATECH) to prevent potential contamination resulting from the dissolution of Pt counter. In electrochemical experiments, 10 $\mu \mathrm{L}$ of the solution of as-prepared materials $(2.5 \mathrm{M})$ were loaded on the glassy carbon. Each compartment was filled with $30 \mathrm{~mL}$ pre-bubbled $\mathrm{CO}_{2}$-saturated 0.5 $\mathrm{M} \mathrm{KHCO}_{3}$, whose $\mathrm{pH}$ changed from 8.6 to 7.2 , and the $\mathrm{CO}_{2}$ flow was kept at 100 $\mathrm{sccm}$ for 10 more mins in the cathode compartment to build an air-free atmosphere for the later detection of as-prepared materials' electrocatalytic activity for $\mathrm{CO}_{2}$ reduction. Several electrochemical techniques were employed in the study, including cyclic voltammograms (CV), chronoamperometry (CA), and electrochemical redox shuttle (R.S.). CVs were conducted in the potential interval between $-0.35 \mathrm{~V}$ and $-1.05 \mathrm{~V}$ at a scan rate $100 \mathrm{mV} / \mathrm{s}$. CA was performed at stated potentials. R.S. was adopted at stated potentials and at stated time intervals (one may refer to Supplementary Fig. 6 for the potential map). Potentials listed in the article were iR-corrected and referenced to the RHE (short for reversible hydrogen electrode) scale by Eq. (3). The $\mathrm{pH}$ of 7.2 was used for the conversion, since the value before and after $\mathrm{CO}_{2} \mathrm{RR}$ treatment stayed constant at 7.2. The iR drop was determined using impedance measurement technique (ZIR) available in the potentiostat.

$$
E_{\mathrm{RHE}}=E_{\mathrm{Ag} / \mathrm{AgCl}}+0.21+0.592 \times \mathrm{pH}-i R
$$

Double layer capacitance $\left(\mathrm{C}_{d 1}\right)$ Measurement. A cyclic voltammetry (CV) method was used to study the $C_{\mathrm{dl}}$ of as-prepared catalysts. CVs were conducted under $\mathrm{N}_{2-}$ saturated $0.5 \mathrm{M} \mathrm{KHCO}_{3}$ at various scan rates $(10-300 \mathrm{mV} / \mathrm{s})$. A potential window from 0.1 to $0.2 \mathrm{~V}$ was adopted due to the absence of redox peaks in this region (Supplementary Fig. 3). Later, the anodic and cathodic current density difference of each CV at the center of the potential window was plotted as a function of scan rate, whose slope will automatically give the $\mathrm{C}_{\mathrm{dl}}$.

CO2RR product analysis. Analytical methods for product characterization here have been outlined previously ${ }^{37}$. Gaseous products were evaluated using gas chromatography (GC, Agilent 7890B). The GC was equipped with a thermal conductivity detector (TCD) and a flame ionization detector (FID) in series. The TCD was for $\mathrm{H}_{2}$ and $\mathrm{CO}$ detection, and the FID was for $\mathrm{CH}_{4}$ and $\mathrm{C}_{2} \mathrm{H}_{4}$ detection. As for those products in liquid phase, gas chromatography-mass spectrometry (GC-MS, 5977A) was adopted to detect ethanol and propanol, and nuclear magnetic resonance (NMR, Bruker Advance III $500 \mathrm{MHz}$ ) was used for the detection of formic acid. The faradaic efficiency (F.E.) of each product was calculated by Eq. (4):

$$
\mathrm{FE}(\%)=\frac{\text { moles of target products } \times n \times F}{C} \times 100 \%
$$

where $n$ is the number of electrons transferred, $F$ stands for Faraday's constant $\left(96485 \mathrm{C} \mathrm{mol}^{-1}\right)$, and $C$ represents the total amount of charge passed through a working electrode.

Operando X-ray absorption spectroscopy. Operando X-ray absorption experiments for $\mathrm{Cu}$ K-edge measurement were conducted at beamline BL $17 \mathrm{C}$ of National Synchrotron Radiation Research Center (NSRRC). A three-electrode arrangement (the same setup as those described in electrochemical measurements) was used for the operando measurements; the measurements were performed in customized Teflon reactors with a Kapton tape window, allowing X-ray transmission

Operando quick-scanning $\mathbf{X}$-ray absorption spectroscopy. The measurements for $\mathrm{Cu}$ K-edge absorption were taken at TPS 44A, Hsinchu, Taiwan. The corresponding data were recorded in total-fluorescence-yield mode. The setup of the experiments was stated in the article. To have a quality spectrum, we applied the Quick-XAS mode in a time-resolution of $5 \mathrm{~s}$ for XANES and EXAFS analyses, while for EXAFS fitting the time-resolution was chosen to be $60 \mathrm{~s}$. The X-ray absorption experimental data were collected in total-fluorescence-yield mode, in which the metallic $\mathrm{Cu}$ foil was taken as reference to calibrate the energy scale. Using Demeter, all X-ray absorption spectra were processed by subtracting the baseline of pre-edge and normalizing that of post-edge; such data processing was for both X-ray absorption near edge spectra (XANES) and extended X-ray absorption fine structure (EXAFS) analyses. EXAFS analysis was carried out using Fourier 
transform on $k^{3}$-weighted EXAFS oscillations to assess the contribution of each bond pair to Fourier transform peak. The curve fitting of EXAFS spectra was conducted using the software, REX2000, with FEFF8 program.

Theoretical analysis. All calculations were performed with the DFT plane-wave method utilizing the Vienna ab-initio simulation package (VASP) $)^{57-60}$. We used the projector-augmented-wave method (PAW) ${ }^{61,62}$ in conjunction with generalized gradient-approximation (GGA) calculation, and Perdew-Burke-Ernzerhof (PBE) exchange-correlation functional was applied. For the design of slab models, we used 8, 6, and 12 atomic layers for $\mathrm{Cu}_{2} \mathrm{O}(111), \mathrm{Cu}_{2} \mathrm{O}(110)$, and $\mathrm{Cu}_{2} \mathrm{O}(100)$, respectively, as shown in Supplementary Fig. 36. For the DFT $+\mathrm{U}$ calculations, we chose the cutoff energy at $500 \mathrm{eV}$ with $8 \times 8 \times 8$ and $4 \times 4 \times 1$ k-point mesh for bulk and surfaces models, respectively. On-site Columbic correction $(U=5.2 \mathrm{eV})$ was used to prevent delocalization of $\mathrm{Cu}$ d-orbitals, that has been demonstrated for modeling the previous $\mathrm{Cu}_{2} \mathrm{O}$ system ${ }^{63,25}$. The bottom two atomic layers were kept frozen with the remaining layers fully relaxed for these $\mathrm{Cu}_{2} \mathrm{O}$ slabs. In all cases, the slab calculations included a vacuum region of thickness greater than $15 \AA$, large enough to ensure no interaction between the two slabs. The adsorption energies were calculated based on the following equation,

$$
\Delta E \text { ads }=E[\text { slab }+ \text { adsorbate }]-(E[\text { slab }]+E[\text { adsorbate }])
$$

in which $E[$ slab + adsorbate], $E[$ slab], and $E$ [adsorbate] were the calculated electronic energies of adsorbed species on the above surfaces, clean surfaces, and free molecules, respectively. The climbing-image-nudged-elastic-band (CI-NEB) method $^{25,64-66}$ was applied to locate transition structures; the profile of the potential-energy surface (PES) was constructed accordingly. Frequency calculations were applied to verify the adsorbed intermediates and the transition states (with only one imaginary frequency). Based on the stepwise oxygen-vacancy formation energy, the $\mathrm{Cu}_{2} \mathrm{O}(110)$ surfaces was found to contain the most subtle surface reconstruction among the three common $\mathrm{Cu}_{2} \mathrm{O}$ cases (i.e., (111), (110), and (100)) as illustrated in Supplementary Fig. 36.

\section{Solvent model. To provide an appropriate solvent effect of CO dimerization} reaction, we constructed an explicit water layers (64 water molecules) to represent the hydrogen bond network of the aqueous environment. Water molecules were described by SPC-3f( $\left(\right.$ ) models ${ }^{67}$ using LAMMPS molecular dynamics simulator ${ }^{25}$. The liquid-solid interfaces were brought to equilibrium with $2 \mathrm{~ns}$ pre-equilibrium simulations ${ }^{68}$ at $350 \mathrm{~K}$ while the solid geometry (with adsorbate) remained frozen during the molecular dynamics simulations, being represented by atomic charges (from Bader charges of DFT). The adsorbate and solid structures were also taken from our DFT calculations. After 2 ns of pre-equilibrium, we sampled 10 solvation structures ( $0.2 \mathrm{~ns}$ apart per sample) for the initial state $2 \mathrm{CO}$ (IS), C-C bond coupling transition state (TS), and OCCO final state (FS), followed by solvent structure optimization at DFT-level. Finally, we took the average energy of these 10 structures to represent $\mathrm{E}(\mathrm{IS}), \mathrm{E}(\mathrm{TS})$, and $\mathrm{E}(\mathrm{FS})$ for $\mathrm{CO}-\mathrm{CO}$ coupling process, respectively.

Thermodynamic correction. The relative Gibbs energy in solution $(\Delta G)$ for the free energy difference between any adsorbate pair on the surfaces was defined as $\Delta G=\Delta H-T \Delta S . \Delta H$ was estimated as $\Delta\left(E+\mathrm{ZPE}+E_{\mathrm{vib}}\right)$ with $E$ representing the average electronic energy of DFT under explicit solvation treatment, ZPE representing zero-point energy, and $E_{\text {vib }}$ representing the internal energy correction of vibrational models (the relative translational and rotational contribution for any adsorbate pair was assumed canceled out ${ }^{69,70,25}$. $\Delta S$ was predicted by the vibrational partition function using harmonic vibrations. For the $\mathrm{CO}-\mathrm{CO}$ coupling process, the vibrational modes of two surface $\mathrm{Cu}$ atoms were taken into account. For example, $\overline{\Delta G^{\ddagger}}=\overline{\Delta G}(\mathrm{TS})-\overline{\Delta G}(2 \mathrm{CO})=[\overline{\Delta H}(\mathrm{TS})-T \overline{\Delta S}(\mathrm{TS})]-[\overline{\Delta H}(2 \mathrm{CO})-$ $T \overline{\Delta S}(2 \mathrm{CO})]$ was estimated by each 10 sampled configurations. For the ethanol formation pathway, we did not take into account the explicit solvation effect due to its trivial difference.

\section{Data availability}

The data that support the findings of this study are available from the corresponding author upon reasonable request.

Received: 10 February 2020; Accepted: 19 June 2020;

Published online: 14 July 2020

\section{References}

1. Nitopi, S. et al. Progress and perspectives of electrochemical $\mathrm{CO}_{2}$ reduction on copper in aqueous electrolyte. Chem. Rev. 119, 7610-7672 (2019).

2. Jüttner, K., Galla, U. \& Schmieder, H. Electrochemical approaches to environmental problems in the process industry. Electrochim. Acta 45, 2575-2594 (2000).
3. Simonsson, D. Electrochemistry for a cleaner environment. Chem. Soc. Rev. 26, 181-189 (1997)

4. Rajeshwar, K., Ibanez, J. G. \& Swain, G. M. Electrochemistry and the environment. J. Appl. Electrochem. 24, 1077-1091 (1994).

5. Jouny, M., Luc, W. \& Jiao, F. General techno-economic analysis of $\mathrm{CO}_{2}$ electrolysis systems. Ind. Eng. Chem. Res. 57, 2165-2177 (2018).

6. Hori, Y. in Modern Aspects of Electrochemistry. Vol. 41, p. 89-189 (Springer, 2008).

7. Burdyny, T. \& Smith, W. A. $\mathrm{CO}_{2}$ reduction on gas-diffusion electrodes and why catalytic performance must be assessed at commercially-relevant conditions. Energy Environ. Sci. 12, 1442-1453 (2019).

8. Bard, A. J. \& Faulkner, L. R. in Electrochemical Methods: Fundamentals and Applications. 2nd edn (Wiley, 2001).

9. Verma, S., Kim, B., Jhong, H. "Molly", Ma, S. \& Kenis, P. J. A. A gross-margin model for defining technoeconomic benchmarks in the electroreduction of CO2. ChemSusChem 9, 1972-1979 (2016).

10. Mistry, H. et al. Tuning catalytic selectivity at the mesoscale via interparticle interactions. ACS Catal. 6, 1075-1080 (2016).

11. Reske, R., Mistry, H., Behafarid, F., Cuenya, B. R. \& Strasser, P. Particle size effects in the catalytic electroreduction of $\mathrm{CO}_{2}$ on $\mathrm{Cu}$ nanoparticles. J. Am. Chem. Soc. 136, 6978-6986 (2014).

12. Ma, S. et al. Electroreduction of carbon dioxide to hydrocarbons using bimetallic $\mathrm{Cu}-\mathrm{Pd}$ catalysts with different mixing patterns. J. Am. Chem. Soc. 139, 47-50 (2016).

13. Kim, D., Resasco, J., Yu, Y., Asiri, A. M. \& Yang, P. Synergistic geometric and electronic effects for electrochemical reduction of carbon dioxide using gold-copper bimetallic nanoparticles. Nat. Commun. 5, 4948 (2014).

14. Jedidi, A., Rasul, S., Masih, D., Cavallo, L. \& Takanabe, K. Generation of $\mathrm{Cu}$-In alloy surfaces from $\mathrm{CuInO}_{2}$ as selective catalytic sites for $\mathrm{CO}_{2}$ electroreduction. J. Mater. Chem. A 3, 19085-19092 (2015).

15. Mistry, H. et al. Highly selective plasma-activated copper catalysts for carbon dioxide reduction to ethylene. Nat. Commun. 7, 12123 (2016).

16. Li, C. W., Ciston, J. \& Kanan, M. W. Electroreduction of carbon monoxide to liquid fuel on oxide-derived nanocrystalline copper. Nature 508, 504-507 (2014).

17. $\mathrm{Li}, \mathrm{C}$. \& Kanan, $\mathrm{M} . \mathrm{CO}_{2}$ reduction at low overpotential on $\mathrm{Cu}$ electrodes resulting from the reduction of thick $\mathrm{Cu}_{2} \mathrm{O}$ films. J. Am. Chem. Soc. 134, 7231-7234 (2012).

18. Kas, R. et al. Electrochemical $\mathrm{CO}_{2}$ reduction on $\mathrm{Cu}_{2} \mathrm{O}$-derived copper nanoparticles: controlling the catalytic selectivity of hydrocarbons. Phys. Chem. Chem. Phys. 16, 12194-12201 (2014).

19. Shiratsuchi, R., Aikoh, Y. \& Nogami, G. Pulsed electroreduction of $\mathrm{CO}_{2}$ on copper electrodes. J. Electrochem. Soc. 140, 3479-3482 (1993).

20. Kumar, B. et al. Controlling the product syngas $\mathrm{H}_{2}$ : $\mathrm{CO}$ ratio through pulsedbias electrochemical reduction of $\mathrm{CO}_{2}$ on copper. ACS Catal. 6, 4739-4745 (2016).

21. Duff, C. S. L., Lawrence, M. J. \& Rodriguez, P. Role of the adsorbed oxygen species in the selective electrochemical reduction of $\mathrm{CO}_{2}$ to alcohols and carbonyls on copper electrodes. Angew. Chem. Int. Ed. 56, 12919-12924 (2017).

22. Kimura, K. W. et al. Controlled selectivity of $\mathrm{CO}_{2}$ reduction on copper by pulsing the electrochemical potential. ChemSusChem 11, 1781-1786 (2018).

23. Yano, J. \& Yamasaki, S. Pulse-mode electrochemical reduction of carbon dioxide using copper and copper oxide electrodes for selective ethylene formation. J. Appl. Electrochem. 38, 1721 (2008).

24. Yano, J., Morita, T., Shimano, K., Nagami, Y. \& Yamasaki, S. Selective ethylene formation by pulse-mode electrochemical reduction of carbon dioxide using copper and copper-oxide electrodes. J. Solid State Electrochem. 11, 554-557 (2007).

25. Chang, C.-J. et al. Quantitatively unraveling the redox shuttle of spontaneous oxidation/electroreduction of $\mathrm{CuO}_{\mathrm{x}}$ on silver nanowires using in situ X-ray absorption spectroscopy. ACS Cent. Sci. 5, 1998-2009 (2019).

26. Gu, J., Hsu, C.-S., Bai, L., Chen, H. M. \& Hu, X. Atomically dispersed Fe3+ sites catalyze efficient CO2 electroreduction to CO. Science 364, 1091-1094 (2019).

27. Eilert, A., Roberts, F. S., Friebel, D. \& Nilsson, A. Formation of copper catalysts for $\mathrm{CO}_{2}$ reduction with high ethylene/methane product ratio investigated with in situ X-ray absorption spectroscopy. J. Phys. Chem. Lett. 7, 1466-1470 (2016)

28. Eilert, A. et al. Subsurface oxygen in oxide-derived copper electrocatalysts for carbon dioxide reduction. J. Phys. Chem. Lett. 8, 285-290 (2016).

29. Minguzzi, A. et al. Fixed energy X-ray absorption voltammetry. Anal. Chem. 85, 7009-7013 (2013).

30. Xiong, Y., Yang, Y., Feng, X., DiSalvo, F. J. \& Abruña, H. D. A strategy for increasing the efficiency of the oxygen reduction reaction in $\mathrm{Mn}$-doped cobalt ferrites. J. Am. Chem. Soc. 141, 4412-4421 (2019). 
31. Yang, Y. et al. In situ X-ray absorption spectroscopy of a synergistic Co-Mn oxide catalyst for the oxygen reduction reaction. J. Am. Chem. Soc. 141, 1463-1466 (2019).

32. Tromp, M. et al. Energy dispersive XAFS: characterization of electronically excited states of copper(I) complexes. J. Phys. Chem. B 117, 7381-7387 (2013).

33. Varela, A. S. et al. Electrochemical reduction of $\mathrm{CO}_{2}$ on metal-nitrogen-doped carbon catalysts. ACS Catal. 9, 7270-7284 (2019).

34. Iwasawa, Y., Asakura, K. \& Tada, M. in XAFS Techniques for Catalyst, Nanomaterials, and Surfaces (Springer, 2017).

35. Xiao, H., Goddard, W. A. I., Cheng, T. \& Liu, Y. Cu metal embedded in oxidized matrix catalyst to promote $\mathrm{CO}_{2}$ activation and $\mathrm{CO}$ dimerization for electrochemical reduction of CO2. Proc. Natl Acad. Sci. USA 114, 6685-6688 (2017).

36. Yao, K. X., Yin, X. M., Wang, T. H. \& Zeng, H. C. Synthesis, self-assembly, disassembly, and reassembly of two types of $\mathrm{Cu}_{2} \mathrm{O}$ nanocrystals unifaceted with $\{001\}$ or $\{110\}$ planes. J. Am. Chem. Soc. 132, 6131-6144 (2010).

37. Suen, N.-T. et al. Morphology manipulation of copper nanocrystals and product selectivity in the electrocatalytic reduction of carbon dioxide. ACS Catal. 9, 5217-5222 (2019).

38. Chen, K. \& Xue, D. Ex situ identification of the $\mathrm{Cu}^{+}$long-range diffusion path of a Cu-based anode for lithium ion batteries. Phys. Chem. Chem. Phys. 16, 11168-11172 (2014).

39. Hahn, J. E. et al. Observation of an electric quadrupole transition in the X-ray absorption spectrum of a Cu(II) complex. Chem. Phys. Lett. 88, 595-598 (1982).

40. Lum, Y., Cheng, T., Goddard, I. W. A. \& Ager, J. W. Electrochemical CO reduction builds solvent water into oxygenate products. J. Am. Chem. Soc. 140, 9337-9340 (2018).

41. Montoya, J. H., Shi, C., Chan, K. \& Nørskov, J. K. Theoretical insights into a $\mathrm{CO}$ dimerization mechanism in $\mathrm{CO}_{2}$ electroreduction. J. Phys. Chem. Lett. 6, 2032-2037 (2015).

42. Kuhl, K. P., Cave, E. R., Abram, D. N. \& Jaramillo, T. F. New insights into the electrochemical reduction of carbon dioxide on metallic copper surfaces. Energy Environ. Sci. 5, 7050-7059 (2012).

43. Hung, S.-F. et al. Identification of stabilizing high-valent active sites by operando high-energy resolution fluorescence-detected X-Ray absorption spectroscopy for high efficient water oxidation. J. Am. Chem. Soc. 140, 17263-17270 (2018).

44. Lin, S.-C., Hsu, C.-S., Chiu, S.-Y., Liao, T.-Y. \& Chen, H. M. Edgeless Ag-Pt bimetallic nanocages: in situ monitor plasmon-induced suppression of hydrogen peroxide formation. J. Am. Chem. Soc. 139, 2224-2233 (2017).

45. Zhu, Y. et al. Operando unraveling of the structural and chemical stability of P-substituted $\mathrm{CoSe}_{2}$ electrocatalysts toward hydrogen and oxygen evolution reactions in alkaline electrolyte. ACS Energy Lett. 4, 987-994 (2019).

46. Garche, J. in Encyclopedia of Electrochemical Power Sources (Elsevier, 2009)

47. Stötzel, J., Lützenkirchen-Hecht, D. \& Frahm, R. A new stand-alone QEXAFS data acquisition system for in situ studies. J. Synchrotron Rad. 18, 165-175 (2011).

48. Vitova, T., Hormes, J., Peithmann, K. \& Woike, T. X-ray absorption spectroscopy study of valence and site occupation of copper in $\mathrm{LiNbO}_{3}: \mathrm{Cu}$. Phys. Rev. B 77, 144103 (2008).

49. Riegg, S., Reller, A., Loidl, A. \& Ebbinghaus, S. G. Valence properties of Cu and $\mathrm{Ru}$ in titanium-substituted $\mathrm{LnCu}_{3} \mathrm{Ru}_{4} \mathrm{O}_{12+\delta}(\mathrm{Ln}=\mathrm{La}, \mathrm{Pr}, \mathrm{Nd})$ investigated by XANES and TGA. Dalton Trans. 44, 10852-10859 (2015).

50. Raciti, D., Livi, K. J. \& Wang, C. Highly dense Cu nanowires for lowoverpotential $\mathrm{CO}_{2}$ reduction. Nano Lett. 15, 6829-6835 (2015)

51. Lukowski, M. A., Dnaiel, A. S., Meng, F., Forticaux, A. \& Jin, S. Enhanced hydrogen evolution catalysis from chemically exfoliated metallic $\mathrm{MoS}_{2}$ nanosheets. J. Am. Chem. Soc. 135, 10274-10277 (2013).

52. Feng, X., Jiang, K., Fan, S. \& Kanan, M. W. A direct grain-boundary-activity correlation for $\mathrm{CO}$ electroreduction on $\mathrm{Cu}$ nanoparticles. ACS Cent. Sci. 2, 169-174 (2016).

53. Mariano, R. G., McKelvey, K., White, H. S. \& Kanan, M. W. Selective increase in $\mathrm{CO}_{2}$ electroreduction activity at grain-boundary surface terminations. Science 358, 1187-1192 (2017).

54. Pérez-Gallent, E., Figueiredo, M. C., Calle-Vallejo, F. \& Koper, M. T. M. Spectroscopic observation of a hydrogenated CO dimer intermediate during $\mathrm{CO}$ reduction on $\mathrm{Cu}(100)$ electrodes. Angew. Chem. Int. Ed. 56, 3621-3624 (2017).

55. Xiao, H., Cheng, T. \& Goddard, W. A. Atomistic mechanisms underlying selectivities in $\mathrm{C} 1$ and $\mathrm{C} 2$ products from electrochemical reduction of $\mathrm{CO}$ on Cu(111). J. Am. Chem. Soc. 139, 130-136 (2016)

56. Chang, C.-C., Li, E. Y. \& Tsai, M.-K. A computational exploration of $\mathrm{CO}_{2}$ reduction via CO dimerization on mixed-valence copper oxide surface. Phys. Chem. Chem. Phys. 20, 16906-16909 (2018).

57. Kresse, G. \& Hafner, J. Ab initio molecular dynamics for liquid metals. Phys. Rev. B 47, 558-561 (1993).
58. Kresse, G. \& Hafner, J. Ab initio molecular-dynamics simulation of the liquidmetal-amorphous-semiconductor transition in germanium. Phys. Rev. B 49, 14251-14269 (1994)

59. Kresse, G. \& Furthmüller, J. Efficient iterative schemes for ab initio totalenergy calculations using a plane-wave basis set. Phys. Rev. B 54, 11169-11186 (1996).

60. Kresse, G. \& Furthmüller, J. Efficiency of ab-initio total energy calculations for metals and semiconductors using a plane-wave basis set. Comp. Mater. Sci. 6, 15-50 (1996).

61. Kresse, G. \& Joubert, D. From ultrasoft pseudopotentials to the projector augmented-wave method. Phys. Rev. B 59, 1758-1775 (1998).

62. Blöchl, P. E. Projector augmented-wave method. Phys. Rev. B 50, 17953-17979 (1994).

63. Scanlon, D. O., Morgan, B. J. \& Watson, G. W. Modeling the polaronic nature of p-type defects in $\mathrm{Cu}_{2} \mathrm{O}$ : the failure of GGA and GGA + U. J. Chem. Phys. 131, 124703 (2009).

64. Sheppard, D., Terrell, R. \& Henkelman, G. Optimization methods for finding minimum energy paths. J. Chem. Phys. 128, 134106 (2008).

65. Sheppard, D. \& Henkelman, G. Paths to which the nudged elastic band converges. J. Comput. Chem. 32, 1769-1771 (2011).

66. Henkelman, G., Uberuaga, B. P. \& Jónsson, H. A climbing image nudged elastic band method for finding saddle points and minimum energy paths. $J$. Chem. Phys. 113, 9901-9904 (2000).

67. Huang, I.-S. \& Tsai, M.-K. Interplay between polarizability and hydrogen bond network of water: reparametrizing the flexible single-point-charge water model by the nonlinear adaptive force matching approach. J. Phys. Chem. 122, 4654-4662 (2018)

68. Plimpton, S. Fast parallel algorithms for short-range molecular dynamics. J. Comput. Phys. 117, 1-19 (1995).

69. Blaylock, D. W., Ogura, T., Green, W. H. \& Beran, G. J. O. Computational investigation of thermochemistry and kinetics of steam methane reforming on $\mathrm{Ni}(111)$ under realistic conditions. J. Phys. Chem. C 113, 4898-4908 (2009).

70. Monder, D. S. \& Karan, K. Ab initio adsorption thermodynamics of $\mathrm{H}_{2} \mathrm{~S}$ and $\mathrm{H}_{2}$ on $\mathrm{Ni}(111)$ : the importance of thermal corrections and multiple reaction equilibria. J. Phys. Chem. C 114, 22597-22602 (2010).

\section{Acknowledgements}

This study is supported by the Ministry of Science and Technology of Taiwan (108-2628 M-002-004 -RSP, 107-2113-M-003-007, 107-2811-M-003-528, and 108-2113-M-003003). We also thank the innovation-oriented trilateral research fund for young investigators of NTU system (108PNTUS01), thanks to Ms. C.-Y. Chien and Ms. S.-J. Ji of Ministry of Science and Technology (National Taiwan University) for the assistance in SEM and TEM experiments. The technical support from the Advanced nano/microFabrication and Characterization lab at Academia Sinica is acknowledged. We are grateful to the computational resources provided by National Center for HighPerformance Computing of Taiwan and Center for Cloud Computing in National Taiwan Normal University.

\section{Author contributions}

H.M.C. conceived the idea. S.C.L., S.Y.C., and T.Y.L. conducted the majority of electrochemical measurements and of operando XAS experiments. C.C.C. and H.T.P. performed the DFT calculations. C.S.H. provided assistance for electron microscopy analysis. S.C.L. analyzed the overall experimental data under the supervision of H.M.C, while C.C.C. the computational results under the supervision of M.K.T.; guided by H.M.C., M.K.T., and W.H.C.; S.C.L. and C.C.C. wrote the manuscript. All the other authors discussed the results and assisted during the manuscript preparation.

\section{Competing interests}

The authors declare no competing interests.

\section{Additional information}

Supplementary information is available for this paper at https://doi.org/10.1038/s41467 020-17231-3.

Correspondence and requests for materials should be addressed to M.-K.T. or H.M.C.

Peer review information Nature Communications thanks the anonymous reviewers for their contribution to the peer review of this work.

Reprints and permission information is available at http://www.nature.com/reprints

Publisher's note Springer Nature remains neutral with regard to jurisdictional claims in published maps and institutional affiliations. 
(c) (i) Open Access This article is licensed under a Creative Commons Attribution 4.0 International License, which permits use, sharing, adaptation, distribution and reproduction in any medium or format, as long as you give appropriate credit to the original author(s) and the source, provide a link to the Creative Commons license, and indicate if changes were made. The images or other third party material in this article are included in the article's Creative Commons license, unless indicated otherwise in a credit line to the material. If material is not included in the article's Creative Commons license and your intended use is not permitted by statutory regulation or exceeds the permitted use, you will need to obtain permission directly from the copyright holder. To view a copy of this license, visit http://creativecommons.org/ licenses/by/4.0/.

(C) The Author(s) 2020 